\title{
Previdência social e migração: O que acontece com os trabalhadores que saem do Brasil e se aposentam na Espanha e em Portugal?
}

\author{
Giselle Mazotto de Carvalho ${ }^{1}$ \\ Luís Eduardo Afonso ${ }^{2}$
}

\section{Resumo}

Este artigo visa analisar os impactos sobre trabalhadores brasileiros que migram durante a vida ativa para Espanha ou para Portugal e se aposentam nestes países. Isto é realizado com base nos acordos previdenciários entre essas nações, levando em consideração as diferentes regras de contribuição, condições de elegibilidade e regras de cálculo da aposentadoria. São calculados os valores da aposentadoria e três indicadores previdenciários: Taxa de Reposição (TR), Taxa Interna de Retorno (TIR) e Alíquota Necessária (AliqNec) para cada situação analisada. Adicionalmente, propõe-se um indicador para mensurar a variação na contribuição necessária para custear o benefício no país de destino, decorrente da migração. Os principais resultados mostram que, embora os valores de TR possam aumentar com a migração (a não ser para os indivíduos de renda mais alta), os demais indicadores tendem a ser menores, em particular pela idade de aposentadoria mais elevada em Portugal e na Espanha.

\section{Palavras-Chave}

Previdência social. Aposentadoria. Migração. Indicadores previdenciários.

\begin{abstract}
This article aims to analyze the impacts on Brazilian workers who migrate during their working lives to Spain or Portugal and retire in these countries. This is done from the perspective of the worker, based on the social security agreements between these nations, considering the different rules of contribution, eligibility conditions and calculation of old-age benefits. Pension values and three pension indicators are calculated: Replacement Rate (RR), Internal Rate of Return (IRR) and Necessary Contribution Rate (AliqNec) for each situation analyzed. Additionally, an indicator is proposed to measure the variation in the contribution needed to fund the benefit

1 Atuária - Itaú Unibanco - End.: Praça Alfredo Egydio de Souza Aranha, 100 - São Paulo/SP - Brasil. CEP: 04344-902 - E-mail: giselle.mazzotto@gmail.com - ORCID: https://orcid.org/0000-00019728-4967.

2 Professor - Bolsista de Produtividade em Pesquisa do CNPq - Nível 2 - Projeto n. o - 304625/2019-1 Universidade de São Paulo - Faculdade de Economia, Administração, Contabilidade e Atuária.

End.: Av. Prof. Luciano Gualberto 908 - Prédio FEA 3, sala 215 - CEP: 05508-010 - São Paulo/SP. Brasil - E-mail: lafonso@usp.br - ORCID: https://orcid.org/0000-0003-4639-8299.

Recebido: 04/09/2018 Aceito: 16/07/2020

Editor responsável: Dante Mendes Aldrighi
\end{abstract}

(c) (i) (\$) Esta obra está licenciada com uma Licença Creative Commons Atribuição-Não Comercial 4.0 Internacional. 
in the destination country, resulting from the migration. The main results show that, although the RR values may increase with migration (except for individuals with higher income), the other indicators tend to be lower, in particular due to the higher retirement age in Portugal and Spain.

\section{Keywords}

Pension system. Retirement. Migration. Pension indicators.

\section{JEL Classification}

H55. J26. J15.

\section{Introdução}

Deslocamentos de indivíduos entre diferentes localidades sempre existiram ao longo da história. Processos migratórios foram importantes para a constituição de diversas nações. Mais recentemente, o processo de globalização gerou assimetrias no processo migratório, particularmente com o aumento da proporção de trabalhadores de baixa renda e baixa qualificação (Czaika e de Haas 2014). Por este motivo, o trânsito de trabalhadores que exerceram parte de sua vida laboral em seu país de origem, migraram durante sua vida ativa e se aposentam no país de destino, pode ser relevante para as políticas de proteção social.

O número de migrantes internacionais aumentou mais de 49\% em 17 anos. Em 2000, esse número representava cerca de 173 milhões de pessoas, aumentando para cerca de 258 milhões em 2017. Os migrantes internacionais totalizavam cerca de 3,4\% da população mundial em 2017 versus 2,8\% em 1990 (United Nations 2017). A intensificação da dinâmica migratória insere-se no debate sobre os sistemas previdenciários, sendo alvo de atenção da International Social Security Association (ISSA, 2010). Para esta organização, as sete principais mudanças demográficas são: migração envelhecimento, mudanças nas estruturas familiares, mudanças no mercado de trabalho, urbanização, dessincronização do ciclo de vida e mudanças na estrutura social. Esta qualificação já evidencia a relevância do processo migratório, visto que é esperado que o migrante seja inserido na estrutura de proteção social do país de destino. E, como aponta Borjas (1999, 1699), parcela expressiva do debate sobre políticas migratórias é motivado pelo impacto que os migrantes representam para a estrutura de proteção social. 
O fluxo migratório internacional está também relacionado com elementos da política externa dos países. Uma evidência são os acordos internacionais de previdência social, tratados firmados entre dois países (bilaterais) e/ou mais países (multilaterais) com o objetivo de assegurar os direitos previdenciários aos trabalhadores migrantes. Atualmente, o Brasil possui acordos bilaterais com Alemanha, Bélgica, Cabo Verde, Canadá, Chile, Coreia do Sul, Espanha, França, Grécia, Itália, Japão, Luxemburgo e Portugal, além dos acordos multilaterais do Mercosul (que inclui Argentina, Uruguai e Paraguai) e Iberoamericano (com países das Américas do Sul e Central, além de Portugal e Espanha).

A migração também é parte da agenda política nacional. Em 24 de maio de 2017, foi sancionada a nova Lei de Migração, que regula a entrada e permanência de estrangeiros no país, revogando o Estatuto do Estrangeiro criado em 1980. Este estatuto tinha como princípio a segurança nacional. Já a nova lei tem foco nos direitos humanos, com tratamento igualitário para os migrantes (Barbon 2017).

Há um caso de particular interesse para a previdência social: os indivíduos que migram durante a vida ativa. Estes fazem parte de suas contribuições previdenciárias de acordo as regras do país original e parte no país que os recebeu, onde conseguem se aposentar. Como as regras previdenciárias são diferentes, pode haver algum tipo de subsídio cruzado, pois o montante de contribuições pode ser maior ou menor do que o necessário para custear o benefício obtido. Tanto receitas, quanto despesas previdenciárias são impactadas. Esta situação tende a se tornar mais relevante, à medida que a portabilidade de benefícios sociais vem se tornando mais expressiva (Holzmann e Wels 2020).

Com base nesse quadro, este artigo tem por objetivo analisar os impactos decorrentes da migração de trabalhadores brasileiros para Espanha ou para Portugal. Isto é feito sob a ótica do trabalhador, ou seja, é feita a quantificação de todos os fluxos de renda e de contribuições previdenciárias desde sua entrada no mercado de trabalho, até o seu falecimento. Com este fim é empregado um modelo de ciclo de vida simplificado, que, além do período laboral, incorpora o período de recebimento das aposentadorias. São calculados os valores da aposentadoria e três indicadores previdenciários: Taxa de Reposição, Taxa Interna de Retorno e Alíquota Necessária. Adicionalmente, de forma que se supõe original, propõe-se um indicador 
para mensurar a variação na contribuição necessária para custear o benefício no país de destino, decorrente da migração.

O artigo contém cinco seções, incluindo esta introdução. A segunda seção apresenta a fundamentação teórica sobre os sistemas previdenciários e o processo migratório. Os procedimentos metodológicos são descritos na terceira seção. A quarta seção expõe os resultados. Por último, a quinta seção apresenta as conclusões do artigo.

\section{Fundamentação teórica}

Nesta seção, são abordados alguns aspectos conceituais dos sistemas previdenciários. Na sequência serão apresentadas algumas das principais teorias sobre o processo migratório. Na terceira parte será abordada a relação entre previdência e migração.

\subsection{Sistemas previdenciários}

A seguridade social pode ser definida como um conjunto de programas que englobam a saúde, previdência, assistência e proteção ao emprego. (International Labour Organization (ILO) 2014). Dentre seus componentes destaca-se aqui a previdência social. Esta pode ser definida como um contrato social complexo, de gerenciamento de riscos ligados à geração e reposição de renda, com ênfase na inatividade. Tem natureza intertemporal, sendo mediada pelo governo, com diversas gerações sobrepostas e variadas dimensões de heterogeneidade.

Sistemas previdenciários têm múltiplas funções, conforme apontado no texto clássico de Barr e Diamond (2006). Há quatro objetivos primários: suavização do consumo, provisão de seguro, redução da pobreza e redistribuição de renda. A suavização do consumo é um processo individual de transferência de renda da fase ativa para a fase inativa, de forma a construir uma trajetória ótima de consumo ao longo do ciclo de vida, proporcionando segurança econômica na velhice. O objetivo de seguro, por sua vez, consiste no fato de a previdência social ser um mecanismo de agrupa- 
mento de riscos, pelo qual os indivíduos podem se precaver coletivamente, de forma mais eficiente, de uma série de incertezas, tanto em relação a eventos inesperados durante a vida, quanto em relação à duração da vida. A redução da pobreza decorre de a possibilidade do sistema previdenciário prover renda para indivíduos idosos pobres, e/ou que não pouparam o suficiente para prover seus gastos na velhice. Já a redistribuição de renda pode ocorrer de duas formas: intergeracional ou intrageracional. Como objetivos secundários incluem-se o crescimento econômico e a redução de distorções na alocação de recursos.

De forma muito sintética, há duas dimensões de classificação dos sistemas previdenciários: quanto à organização e da relação entre contribuições e benefícios. No primeiro caso, segundo Pallares-Miralles, Romero, e Whitehouse (2012), os sistemas previdenciários podem ser classificados em regimes de repartição (pay-as-you-go) ou regimes de capitalização (fully funded). Nos regimes de repartição os benefícios pagos aos inativos são financiados pelas contribuições dos indivíduos ativos efetuadas no mesmo período, ao passo que, nos regimes de capitalização ocorre a acumulação individual de recursos, ou seja, o indivíduo ativo custeia seu próprio benefício futuro.

No segundo caso, de acordo com Barr e Diamond (2006) os sistemas podem ser classificados como benefício definido (BD) ou contribuição definida (CD). Na modalidade BD, o benefício a receber está definido previamente por regra, atrelado ao histórico de renda do indivíduo. Já nos regimes $\mathrm{CD}$, o benefício é definido em função das contribuições efetuadas e da taxa de retorno sobre as reservas acumuladas no período. Em geral, regimes de repartição enquadram-se na modalidade benefício definido (BD) e regimes de capitalização na modalidade contribuição definida (CD).

Neste trabalho o foco concentra-se nos regimes de repartição com benefício definido. O primeiro motivo é que este é o arranjo previdenciário típico empregado no pilar básico na maior parte dos países. Isto inclui o RGPS, no caso brasileiro e os regimes de Espanha e Portugal, para os quais se analisa a migração. O segundo motivo é que neste tipo de regime, o reconhecimento dos direitos previdenciários não é imediato, como seria no caso de um regime de capitalização com contribuição definida, conforme apontado no fundamental texto de Settergren e Mikula (2005). 


\subsection{Migrações}

De acordo com a ampla definição dada por Lee (1966), a migração pode ser entendida como uma mudança de residência permanente ou semipermanente. Isto implica uma origem, um destino e um conjunto de obstáculos. O processo migratório é complexo e multifacetado. Por este motivo não pode ser explicado por uma única abordagem teórica. Skeldon (2012) é um dos autores cuja argumentação segue esta linha. Grosso modo, as teorias migratórias têm se baseado em fundamentos microeconômicos (o foco da análise é o indivíduo) e macroeconômicos (levam em consideração os fatores estruturais entre regiões). Resenhas abrangentes destas teorias podem ser encontradas em Massey et al. (1993), Santos et al. (2010), Bodvarsson e Van den Berg (2013) e, principalmente, Borjas (1999). Este último, além de apresentar os modelos teóricos mais relevantes, traz também diversos elementos relevantes da agenda de pesquisa empírica.

Embora estes dois últimos autores apontem que já na obra de Adam Smith podem ser encontrados elementos pertinentes à migração, segundo Campos (2015), Ravenstein (1889) pode ser considerado o precursor dos estudos migratórios. Em seu trabalho, intitulado "The laws of migration", Ravenstein buscou conceber leis gerais para entender as migrações, com base nos dados dos Censos Gerais do Reino Unido de 1871 e 1881. O principal motivo verificado para a ocorrência da migração foi a questão econômica, como a procura por postos de trabalho de melhor remuneração. Já no século XX, a obra de referência é Lee (1966), que propõe um modelo push-pull, em que as migrações estão associadas a fatores negativos (push), capazes de forçar a migração do país de origem, e fatores positivos (pull), responsáveis pela atração dos migrantes ao país de destino.

As contribuições de Lewis (1954) e Ranis e Fei (1961) têm seu foco nas questões ligadas ao desenvolvimento econômico, com a consequente migração de trabalhadores, da área rural para a área urbana, atraídos pelo processo de industrialização. Desta maneira, a migração é pautada por elementos do mercado de trabalho. O deslocamento dos trabalhadores ocorreria de regiões com baixos salários e mão de obra abundante para regiões com elevada remuneração e mão de obra escassa. Ainda segundo esta abordagem, uma vez eliminado o diferencial de renda, a migração tenderia a cessar. 
Massey et al. (1993) apontam que os trabalhos de Sjaastad (1962) e Todaro (1969) inserem a fundamentação microeconômica nas teorias migratórias: indivíduos avaliam racionalmente os custos e benefícios marginais associados à migração. Esta ocorre havendo retorno líquido positivo financeiro, oriundo do deslocamento. Além da diferença de renda, diferenciais nas taxas de emprego também são fatores relevantes. Posteriormente, a literatura tem um acréscimo relevante com a incorporação de modelos inspirados na Teoria do Capital Humano (Becker 1975). Os indivíduos analisam os custos e retornos de suas escolhas e realizam investimentos em si próprios (como formação e treinamento profissional). Sob esta ótica, a migração é compreendida como um investimento em capital humano.

A Nova Economia da Migração, também avalia o fenômeno migratório, com base em fundamentos econômicos, entretanto com premissas distintas dos modelos neoclássicos. Segundo Massey et al. (1998, cap. 2), a decisão de migrar não é individual, mas sim coletiva, no âmbito das famílias ou dos domicílios. Os indivíduos agem coletivamente não apenas visando maximizar os rendimentos esperados, mas também para minimizar os riscos e incertezas econômicas.

Finalmente, existem vertentes teóricas que consideram os fatores sociais e culturais como determinantes das migrações. Uma delas destaca o papel desempenhado pelas redes sociais. Segundo Massey et al. (1993), as redes sociais podem ser definidas como um conjunto de laços interpessoais que conectam migrantes, ex-migrantes e não migrantes nas áreas de origem e de destino. Essas redes constituem um tipo de capital social pelo qual os indivíduos podem ter acesso ao mercado de trabalho no exterior. Para Taylor (1986, 196, citado por Campos 2015), as redes sociais reduzem o risco, ao prover informações relevantes para os migrantes.

Esta sucinta revisão da literatura permite concluir que não existe uma teoria única que seja capaz de explicar totalmente o fenômeno migratório, sendo este mais bem compreendido pelo uso combinado de mais de um arcabouço teórico. As interpretações baseadas nos aspectos econômicos ressaltam o papel dos diferenciais de remuneração entre as áreas de origem e de destino. Neste caso, a decisão de migrar, individual ou coletiva, visa maximizar os rendimentos esperados. Já outras concepções, complementam tal compreensão, ao lançar luz sobre o papel das interações sociais como forma de auxílio e incentivo para possíveis migrantes. É possível inferir que a literatura não contempla um papel determinante para 
as estruturas de proteção social no processo migratório, particularmente a previdência social. Esta lacuna, explorada na próxima seção, constitui o motivador fundamental deste artigo.

\subsection{Previdência social e migrações: uma relação (ainda) pouco explorada}

Embora haja um conjunto expressivo de trabalhos sobre proteção social (com destaque para a previdência) e sobre processos migratórios, a literatura que relaciona ambos os temas ainda parece ser incipiente. Este fato vai de encontro ao exposto em International Social Security Association (ISSA) (2018) que aponta a proteção aos migrantes como um dos dez desafios aos sistemas previdenciários. De certa forma, parece haver mais preocupação com esse tema por parte de organismos como a International Labor Organization ou o World Bank, do que da academia. Nesta literatura, o elemento fundamental é a portabilidade de benefícios previdenciários. Seguindo Genser e Holzmann (2020), define-se portabilidade como a manutenção, preservação ou a transferência de direitos previdenciários de um sistema previdenciário para outro, em particular quando da migração do trabalhador para outro país durante sua fase laboral.

Um dos primeiros trabalhos a chamar a atenção para os acordos de proteção social foi Tamagno (1994). O autor aponta que a intensificação do processo migratório entre países desenvolvidos nos anos 1970 e 1980 (em detrimento da migração para países de renda mais baixa) foi em parte motivado pela existência de uma rede de proteção comum, existente desde a década de 1950. Entretanto, no final do século XX, o fluxo migratório originado dos países menos desenvolvidos intensificou-se. Porém, neste caso, o número de acordos era bastante reduzido, o que pode gerar um coverage gap, com preocupantes impactos sociais. O autor aponta a existência de quatro elementos fundamentais para um acordo de proteção previdenciária: base técnica, reciprocidade, solvência financeira e capacidade administrativa.

Na década seguinte, Forteza (2010) voltou ao tema, focando primordialmente a relação entre os acordos de proteção e a mobilidade da mão de obra na região do Caribe. Dois pontos são merecedores de destaque em seu trabalho. O primeiro é chamar a atenção para eventuais perdas que poderiam ocorrer quando das migrações, devido às diferenças de regras 
previdenciárias não contempladas adequadamente nos acordos. $\mathrm{O}$ segundo é intuir que tais diferenças poderiam levar a alguma forma de subsídio cruzado entre os países signatários. Na mesma linha, Sabates-Wheeler e Koettl (2010) lançam luz sobre a falta de proteção social associada às migrações Sul-Sul. Os autores destacam questões como falhas nos programas de seguridade social nos países de baixos rendimentos, além da falta de portabilidade de direitos. Dentre as principais recomendações deste policy paper está a criação de uma rede integrada de proteção social, associada às políticas migratórias. A premência destas indicações é reforçada por Avato, Koettl, e Sabates-Wheeler (2010), que apontam a existência de quase 187 milhões de migrantes no início dos anos 2000. Seguindo na mesma trilha, Fornalé (2017) aponta, com base na experiência do Mercosul e da Asean (sudeste asiático), que os acordos sejam multilaterais e não feitos apenas entre dois países.

Recentemente, um grupo de novas contribuições, talvez motivadas pelo incremento de fluxo migratório para o continente europeu, expandiu a literatura, tendo como destaque os trabalhos de Robert Holzmann (Holzmann 2016; Holzmann, Wels, e Dale 2016a; 2016b; 2016c; 2016d). Nestes papers são analisadas a portabilidade de benefícios previdenciários em quatro corredores migratórios Sul-Norte (Turquia-Áustria, Turquia-Alemanha, Marrocos-Bélgica e Marrocos-França). A avaliação foi feita com base nos critérios de justiça individual, justiça fiscal e eficácia burocrática. Em relação ao primeiro, os movimentos migratórios não deveriam gerar benefícios de aposentadoria mais baixos do que se o trabalhador tivesse ficado em seu país de origem. A justiça fiscal determina que nenhum país deve obter benefícios fiscais ou ser prejudicado em decorrência de um acordo internacional de seguridade social. Já a eficácia burocrática refere-se à baixa carga burocrática, disponibilidade de informações e à facilidade para a solicitação de aposentadoria dos migrantes.

O conjunto de trabalhos em que se trata de forma quantitativa da relação entre sistemas previdenciários e migração é ainda mais reduzido. Um dos primeiros papers digno de nota é Greenwood et al.(1999). Os autores chegam à conclusão de que a existência de regimes de previdência nos países de origem pode representar um desincentivo à migração para os EUA, particularmente se as transferências aos idosos são entendidas como uma forma de transferência de renda. Mas esta conclusão depende também da portabilidade entre os sistemas previdenciários. Posteriormente, este resultado foi estendido por Greenwood e Mcdowell (2011), que mostram 
que esta influência é diferenciada, de acordo com as qualificações dos migrantes. E que outros programas, como seguro-desemprego ou saúde também têm impacto distinto nos fluxos migratórios.

Cohen e Iams (2007) avaliam a adequação dos benefícios previdenciários da previdência social dos EUA, para nascidos no país e para imigrantes. A conclusão mais importante é que, para os indivíduos do segundo grupo, a taxa interna de retorno e a relação entre benefícios e contribuições são inferiores ao nativos, ainda que ambas venham aumentando para as gerações mais novas. Bridges e Choudhury (2007) chegam à conclusão similar sobre o diferencial entre nativos e migrantes, ao examinar somente aqueles que se encontravam perto da aposentadoria. Por outro lado, Sevak e Schmidt (2014), ponderam que, uma vez controladas as características observáveis, a riqueza previdenciária líquida dos migrantes é mais elevada.

A partir da revisão da literatura, percebe-se que há uma lacuna passível de ser explorada: a ausência de trabalhos que empreguem metodologias quantitativas para tratar conjuntamente de temas ligados às migrações e à previdência. Além disso, a maioria dos artigos concentra-se nos aspectos conceituais da portabilidade de benefícios da seguridade social. Conforme apontam Holzmann e Werding (2015), o tópico carece de estudos dos experts da área de proteção social. Por um lado, há contribuições com a ótica jurídica, sobre os tratados de proteção. De outro, há um conjunto de trabalhos sobre temas específicos. Por exemplo, há autores que buscam relacionar o sistema previdenciário com o apoio popular à entrada de novos migrantes (Lacomba e Lagos 2010; Di Liddo 2018). Há também uma linha que parece ser promissora, que estuda os efeitos da migração sobre as receitas, despesas e a sustentabilidade dos sistemas previdenciários, usualmente de forma agregada (Collado, Iturbe-Ormaetxe, e Valera 2004; Alves et al. 2019). Finalmente, com base na literatura de claiming behavior e na heterogeneidade intrageracional, Lopez e Slavov (2020) mostram que migrantes nos EUA tendem a postergar a aposentadoria, comparativamente aos nativos.

Esses trabalhos apresentados no parágrafo anterior, de forma geral, tratam especificamente da comparação entre nativos e migrantes, ou do impacto agregado que estes últimos possam ter sobre os sistemas previdenciários. Entretanto, não foram encontrados na revisão bibliográfica contribuições relevantes que enfoquem especificamente as questões distributivas e os subsídios cruzados, sob a ótica dos trabalhadores, tema tão relevante na 
literatura previdenciária. Em particular, a relação entre os indicadores previdenciários e a decisão de migração, originada da portabilidade de benefícios, parece não ter sido abordada ainda. Desta forma, considera-se que há um gap que pode ser explorado.

Neste trabalho, o arcabouço teórico está ligado à literatura com microfundamentação econômica, na tradição originada dos trabalhos de Becker (1975), Sjaastad (1962) e Todaro (1969). Considera-se que migração é uma decisão individual, em que o trabalhador avalia os custos e benefícios econômicos decorrentes de sua decisão. Nesta análise são levados em conta dois aspectos fundamentais aos sistemas previdenciários: as contribuições previdenciárias efetuadas (nos países de origem e de destino) e o montante de benefícios de aposentadoria recebidos no país de destino. Em particular, dados os objetivos do artigo, é necessário que tais regimes tenham organização similar, da forma repartição - benefício definido. Com tal fim são calculados os indicadores previdenciários usuais da literatura, apresentados na próxima seção. Adicionalmente é proposto um novo indicador, de forma a captar uma especificidade do mecanismo de reconhecimento das contribuições previdenciárias.

\section{Metodologia}

Esta seção apresenta as quatro etapas do procedimento metodológico do artigo. A primeira é representar os eventos ao longo da vida ativa e da aposentadoria do trabalhador migrante. A segunda etapa consiste no reporte das regras previdenciárias dos três países. A terceira etapa corresponde à definição dos indicadores previdenciários utilizados nos cálculos. Finalizando, são explicitadas as premissas empregadas.

\subsection{Ciclo de vida do trabalhador migrante}

A trajetória de rendimentos, contribuições e benefícios previdenciários de um trabalhador pode ser compreendida com o emprego de um modelo de ciclo de vida simplificado, na tradição iniciada por Modigliani e Brumberg (1954). Neste trabalho emprega-se a metodologia dos indivíduos representativos. A Figura 1 apresenta uma representação desse modelo, já incorporando a migração durante a vida ativa. 


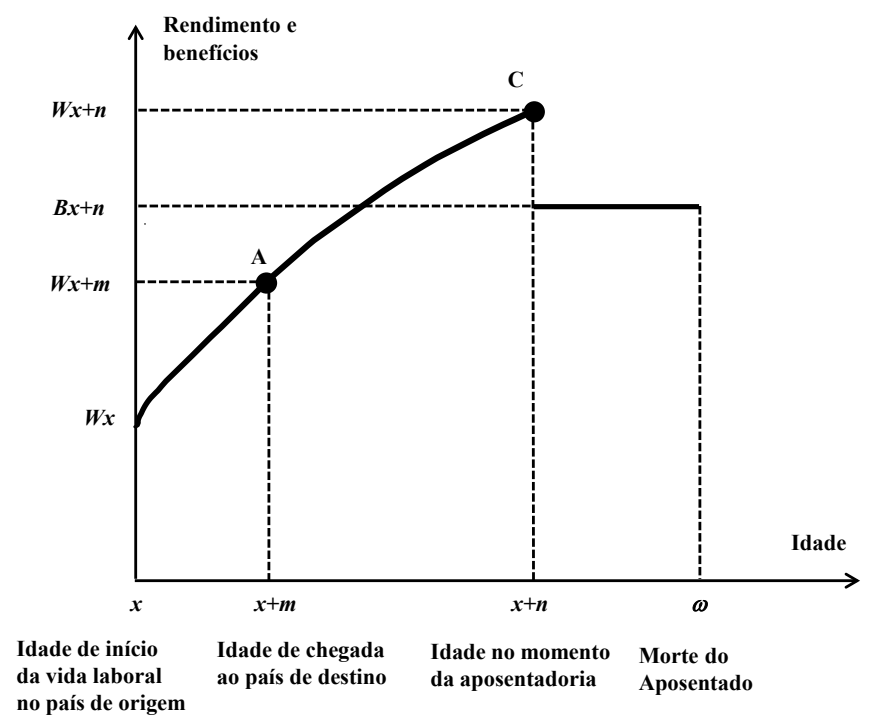

Figura 1 - Ciclo de vida de um trabalhador migrante representativo

Fonte: elaborado pelos autores.

O indivíduo inicia sua vida laboral no país de origem com idade $x$, com renda $W_{x}$. Sua renda cresce com sua experiência no mercado de trabalho, conforme fato estilizado da literatura. Com a idade $x+m$ (ponto A), migra permanentemente para outro país, quando sua renda é $W_{x+m}$. Por simplificação, é mostrado um caso particular em que são feitas duas suposições sobre a renda: crescimento monotônico durante a vida ativa (à mesma taxa, antes e depois da migração) e inexistência de descontinuidade na renda (valor maior ou menor após a migração). O indivíduo continua no mercado de trabalho e se aposenta com $x+n$ anos (ponto C), quando sua renda é $W_{x+n}$. A partir deste instante, passa a receber um benefício de valor real $B_{x+n}$ constante, até a sua morte, com a idade terminal $\omega$.

\subsection{Regras previdenciárias}

Uma vez representado o ciclo de vida simplificado relevante para a previdência social, é necessário apresentar as regras previdenciárias dos três países. Particularmente, são relevantes três informações: o cálculo das contribuições, a idade de aposentadoria e a forma de cálculo dos benefí- 
cios. Por comparabilidade, supõe-se que os trabalhadores representativos estão no setor privado formal urbano. Estes trabalhadores devem atender aos requisitos mínimos para requerer a Aposentadoria por Tempo de Contribuição (ATC) do INSS (caso brasileiro) e Aposentadoria por Tempo de Contribuição e Idade Mínima (casos português e espanhol).

Portugal e Espanha possuem acordos previdenciários internacionais com o Brasil, ambos em vigor desde 1995. Estes acordos garantem o reconhecimento do período contributivo para migrantes que tenham contribuído em ambos os países signatários. A concessão de benefícios deve obedecer os termos da legislação do país de destino (INSS 2007).

\subsubsection{Brasil}

No Brasil, a contribuição previdenciária do empregado incide sobre seu salário de contribuição, remuneração compreendida entre o piso de $\mathrm{R} \$ 937,00$, equivalente a 1 salário mínimo (SM) e o teto de $\mathrm{R} \$ 5.531,31$ $(5,90 \mathrm{SM})$. Estes eram os valores vigentes em 2017, ano de referência para todas as informações apresentadas nesta seção. $\mathrm{O}$ empregador contribui com 20\% do salário do empregado, sem limite. Para este último, a alíquota varia de acordo com a renda. Ao salário de contribuição de até $\mathrm{R} \$ 1.659,38$ corresponde a alíquota de 8\%; a faixa entre $\mathrm{R} \$ 1.659,39$ e $\mathrm{R} \$ 2.765,66$ tem alíquota de $9 \%$ e valores no intervalo entre $\mathrm{R} \$ 2.765,66$ e $\mathrm{R} \$ 5.531,31$ têm alíquota de $11 \%$.

A Aposentadoria por Tempo de Contribuição (ATC) tem como único requisito o tempo de contribuição mínimo de 30 anos para mulheres e 35 anos para os homens. O valor do benefício é calculado por meio da multiplicação da média $M$ dos $80 \%$ maiores salários de contribuição pelo Fator Previdenciário $f$, como mostram as expressões 1 e 2 . Nestas, TC é o tempo de contribuição; $a$ é a alíquota de contribuição (fixa em 0,31); Es é expectativa de sobrevida e $I d$ é a idade, ambas no momento da aposentadoria. No cálculo do fator são adicionados cinco anos ao tempo de contribuição das mulheres. Em 2017, os valores mínimo e máximo dos benefícios eram os mesmos do piso e do teto do salário de contribuição. 


$$
\begin{gathered}
\text { Aposentadoria }=M \cdot f \\
f=\frac{T C \cdot a}{E s}\left(1+\frac{I d+T C \cdot a}{100}\right)
\end{gathered}
$$

A Lei 13.183 alterou a aplicação do fator, ao criar a Regra 85/95 Progressiva. Se no momento da aposentadoria a soma entre a idade Id e o período contributivo TC for menor do que 85 (mulheres) e 95 (homens), a incidência do fator é obrigatória; caso contrário, o fator só será aplicado se for vantajoso para o trabalhador. Os valores iniciais de 85/95 irão aumentar até 2026, quando a soma para as mulheres deverá resultar em 90, e para os homens em 100, conforme a Tabela 1. Em 2017, os valores mínimo e máximo dos benefícios eram, respectivamente, $\mathrm{R} \$ 937,00$ e $\mathrm{R} \$$ 5.531,31.

Tabela 1 - Regra 85/95 Progressiva (soma da idade e do período contributivo) - Brasil

\begin{tabular}{lll}
\hline Período & Mulher & Homem \\
\hline $2017-2018$ & 85 & 95 \\
$2019-2020$ & 86 & 96 \\
$2021-2022$ & 87 & 97 \\
$2023-2024$ & 88 & 98 \\
$2025-2026$ & 89 & 99 \\
2027 em diante & 90 & 100 \\
\hline
\end{tabular}

Fonte: INSS (2019).

\subsubsection{Espanha}

$\mathrm{Na}$ Espanha, a contribuição previdenciária incide sobre o salário de contribuição, remuneração compreendida entre o piso de €825 (1 SM) e $€ 3.642$ (4,4l SM). O empregador contribui com 23,60\% e o empregado com 4,70\% (Social Security Administration (SSA) e International Social Security Association (ISSA) 2016). Em 2017, o trabalhador que atinge a idade mínima de 65 anos deve ter cumprido pelo menos 36,3 anos de período contributivo para requerer a aposentadoria. Este tempo mínimo aumentará progressivamente até 2027, conforme a Tabela 2. (Ministerio de Empleo y Seguridad Social (MESS) 2019). 
Tabela 2 - Tempo mínimo de contribuição - Espanha

\begin{tabular}{lcc}
\hline Ano & Tempo de contribuição (anos) & Idade mínima (anos) \\
\hline 2017 & 36,3 & 65 \\
2018 & 36,6 & 65 \\
2019 & 36,9 & 65 \\
2020 & 37,0 & 65 \\
2021 & 37,3 & 65 \\
2022 & 37,6 & 65 \\
2023 & 37,9 & 65 \\
2024 & 38,0 & 65 \\
2025 & 38,3 & 65 \\
2026 & 38,3 & 65 \\
2027 em diante & 38,6 & 65 \\
\hline
\end{tabular}

Fonte: MESS (2019).

O benefício de aposentadoria é calculado pela aplicação de uma base normativa, que resulta da divisão dos salários de contribuição durante os $n$ meses anteriores à aposentadoria por um divisor $x$. Este fator também terá incrementos até 2022, aumentando dos atuais 240 meses computáveis e divisor 280, para 300 meses computáveis e divisor 350, conforme mostrado na Tabela 3. Em 2017, os valores mínimo e máximo dos benefícios eram respectivamente $€ 637,70$ e $€ 2.573,70$.

Tabela 3 - Base normativa

\begin{tabular}{cccc}
\hline Ano & № de meses computáveis & Divisor & Anos computáveis \\
\hline 2017 & 240 & 280 & 20 \\
2018 & 252 & 294 & 21 \\
2019 & 264 & 308 & 22 \\
2020 & 276 & 322 & 23 \\
2021 & 288 & 336 & 24 \\
2022 em diante & 300 & 350 & 25 \\
\hline
\end{tabular}

Fonte: MESS (2019). 


\subsubsection{Portugal}

Em Portugal, as alíquotas incidentes sobre empregador e empregado são, respectivamente, de $13,81 \%$ e $6,40 \%$ para financiar somente os benefícios de Aposentadoria por Tempo de Contribuição e Idade Mínima. Mas as alíquotas totais são de $23,75 \%$ sobre o empregador e $11 \%$ sobre o empregado. Este valor somando financia os benefícios de velhice, invalidez, doença, morte e maternidade (Social Security Administration (SSA) e International Social Security Association (ISSA) 2016). Com o objetivo de compatibilizar as alíquotas contributivas entre Brasil e Portugal, será utilizada a alíquota total $(34,75 \%)$ para este segundo país, visto que no Brasil não há segregação de alíquotas para financiamento de espécie de benefícios específicos. O cômputo da idade mínima de aposentadoria sofreu alterações em 2014. Segundo a Direção-Geral da Segurança Social (DGSS) 2020), esta passou a variar em função da expectativa média de vida aos 65 anos. Em 2017, a idade mínima era de 66,3 anos, com acréscimo de um mês a cada ano. Além da idade mínima, também é necessário haver no mínimo 15 anos de período contributivo.

O benefício de aposentadoria é calculado por meio da multiplicação da Remuneração de Referência $R R$ pela Taxa Global de Formação TGF, conforme mostra a Equação 3 (DGSS 2020). O valor de $R R$ resulta da divisão entre o total de remunerações $T R$ da carreira contributiva do indivíduo pelo resultado do produto do número de anos civis com registro de remunerações $n$ - limitado a 40 anos - por 14, conforme apresentado na Equação 4. Ano civil é aquele em que há pelo menos 120 dias de remunerações.

$$
\text { Aposentadoria }=\text { RR.TGF }
$$

$$
R R=\frac{T R}{\min (40, n) 14}
$$

O cálculo da TGF é determinado em função da relação entre o valor da Remuneração de Referência com o Indexante dos Apoios Sociais (IAS), no valor de $€ 421,32$, como mostrado na Tabela 4 . A alíquota que varia entre $2 \%$ e $2,3 \%$ é aplicada ao número de anos civis $n$, com o limite de 40 , conforme mostra a equação 5 . 


$$
T G F=\text { Alíquota } * \text { mín }(40, n)
$$

Tabela 4 - Taxa variável por ano de contribuição, conforme o valor da Remuneração de Referência (RR)

\begin{tabular}{cc}
\hline Remuneração de Referência (RR) por indexação ao IAS & Alíquota (\%) \\
\hline Até 1,1x|AS & 2,30 \\
Superior a 1,1xIAS até 2xIAS & 2,25 \\
Superior a 2xIAS até 4xIAS & 2,20 \\
Superior a 4xIAS até 8xIAS & 2,10 \\
Superior a 8xIAS & 2,00 \\
\hline
\end{tabular}

Fonte: DGSS (2020).

O valor mínimo dos benefícios varia conforme o tempo de contribuição do empregado. Para aqueles que possuam tempo de contribuição inferior a 15 anos, o valor mínimo do benefício é de €264,32, já para a faixa de 15 a 20 anos de contribuição o valor mínimo é de $€ 277,27$, para a faixa de 21 a 30 anos o valor mínimo é de $€ 305,96$ e acima dessa faixa o valor mínimo é de €382,46.

\subsection{Indicadores previdenciários}

Um dos desafios da literatura sobre previdência é a avaliação comparativa de sistemas previdenciários e de seus efeitos sobre os segurados (Dixon 1998; Neysmith e Aronson 2012). Com o intuito de quantificar os efeitos da migração sobre os trabalhadores, são empregados três indicadores de uso recorrente na literatura previdenciária: Taxa de Reposição (TR), Taxa Interna de Retorno (TIR) e Alíquota de Contribuição Necessária (AliqNec).

A Taxa de Reposição $T R$, apresentada na Equação 6, é uma medida relativa do poder de compra real. É dada pela relação entre o primeiro benefício recebido $B_{i t}$ e a última remuneração antes da aposentadoria $W_{i t-1}$ (Afonso 2016).

$$
T R_{i}=\frac{B_{i t}}{W_{i t-1}}
$$


A $T R$, apesar de sua simplicidade e de ser uma proxy imediata da reposição de renda, é uma medida incompleta para se avaliar sistemas previdenciários (Whiteford 1995). Por esse motivo, também é utilizada a Taxa Interna de Retorno TIR, apresentada na Equação 7. Esta é a taxa de desconto que iguala os valores presentes das contribuições (do início da vida ativa até o último período contributivo $N$ ) e dos benefícios recebidos (do momento da aposentadoria até a idade terminal $\omega$ (Liebman 2002). A TIR permite que aspectos como diferentes idades de entrada no mercado de trabalho, ou o adiamento da idade de aposentadoria.

$$
\sum_{t=1}^{N} \frac{\text { Contribuição }_{t}}{\left(1+T I R_{i}\right)^{t}}=\sum_{t=N+1}^{\omega} \frac{\text { Benefício }_{t}}{\left(1+T I R_{i}\right)^{t}}
$$

Por fim, a Alíquota Necessária AliqNec, dada pela Equação 8, representa qual deveria ser a alíquota de contribuição incidente sobre a renda, que igualasse os valores presentes esperados dos benefícios $V P B$ e da renda $V P R$. Quanto maior for seu valor em relação à alíquota efetivamente cobrada sobre cada indivíduo, maior deverá ser o desequilíbrio do sistema previdenciário em seu todo.

$$
\text { AliqNec }_{i}=\frac{\sum_{t=N+1}^{\omega} \frac{\text { Beneficio }_{i t}}{(1+r)^{t}}}{\sum_{t=1}^{N} \frac{\text { Renda }_{i t}}{(1+r)^{t}}}
$$

\subsection{Premissas}

Neste trabalho adota-se a metodologia dos indivíduos representativos, bastante utilizada em estudos da área de previdência (Forteza e Ourens 2009; Couch et al. 2017; Clingman, Burkhalter, e Chaplain 2019). É necessário escolher algumas características relevantes, que são empregadas para agrupar os trabalhadores em categorias que permitam uma análise sucinta, tendo como base os objetivos do artigo. Cabe a ressalva, sempre presente nesta metodologia, que um conjunto de trabalhadores pode não estar contemplado nas categorias selecionadas. 
Foram adotadas as seguintes premissas:

- Gênero: são considerados ambos os gêneros em todos os cálculos.

- A migração ocorre apenas um vez, durante o período contributivo. Foram considerados nos cálculos dois fluxos migratórios: BrasilEspanha e Brasil-Portugal.

- Renda inicial no país de origem: são utilizados três patamares em múltiplos do salário mínimo (SM): 1SM, 2SM e 3SM. No Brasil, os valores iniciais são respectivamente de $R \$ 937, R \$ 1.874$ e $R \$ 2.811$. $\mathrm{Na}$ Espanha, os valores são de €825, €1.650 e €2.475. Em Portugal, os valores são de €557, €1.114,00 e €1671. No Brasil, cerca de $85 \%$ dos trabalhadores com carteira de trabalho assinada têm rendimentos inferiores a $3 \mathrm{SM}$.

- Idade no início da vida laboral: 18 anos. Esta idade foi escolhida para captar a entrada um pouco mais tardia dos mais escolarizados no mercado de trabalho.

- Taxa de crescimento da renda e taxa de desconto: supõe-se que as taxas de crescimento salarial e de desconto adotadas são as mesmas. Foram consideradas três possibilidades: $1 \%$ a.a., $2 \%$ a.a. e 3\% a.a., consistentes com a literatura (Godínez-Olivares, Boado-Penas, e Haberman 2016; De La Fuente e Domenéch 2013; Fenge e Peglow 2018).

- Renda inicial no país de destino: Foram consideradas três alternativas em relação à última renda no país de origem: $-50 \%, 0 \%$ e $+50 \%$.

- Idade de chegada ao país de destino: representa a idade em que ocorre a migração. Foram consideradas duas possibilidades: que a migração aconteça 10 ou 20 anos após a entrada no mercado de trabalho

- Taxa de crescimento da renda no país de destino: considerou-se que após a migração não há alteração em relação às taxas adotadas no país de origem.

- Densidade contributiva: supõe-se que não há interrupções do período contributivo durante a vida ativa, ou seja, a densidade contributiva é de $100 \%$.

- Contribuição: as alíquotas de contribuição do empregado e empregador seguem as regras vigentes no sistema previdenciário de cada país. Além disso, supõe-se que quando o indivíduo decide migrar 
para outro país ocorre o reconhecimento do período contributivo no país de origem para o país de destino.

- Tipo de benefício: aposentadoria vitalícia e sem reversão aos dependentes.

- Solicitação do benefício: supõe-se que o trabalhador solicita a aposentadoria assim que atinge os requisitos mínimos necessários (idade e/ou tempo de contribuição).

- Tempo: supõe-se que o indivíduo ingressa no mercado de trabalho em janeiro de 2017, valendo as regras vigentes a cada ano.

- Duração do pagamento do benefício: adotou-se a premissa que o benefício será pago por um período de tempo igual à expectativa de sobrevida no país de destino no momento da aposentadoria, com diferenciação por gênero. Por exemplo, se uma trabalhadora se aposenta em Portugal, aos 70 anos, receberá aposentadoria por 16,5 anos. No caso de um homem, serão 13,8 anos.

- Fluxo de renda e contribuição no país de destino: optou-se por indexar os valores de renda e contribuição ao salário mínimo (SM) vigente. Por exemplo, um indivíduo com renda de 1,5 SM (em reais) no Brasil, que migra para a Espanha, não verifica variação na sua renda no país de destino. Desta forma, sua renda no país europeu passa a ser equivalente a 1,5 SM (em euros). De modo análogo, se o mesmo indivíduo tivesse realizado no país de origem contribuições no montante de $30 \mathrm{SM}$ (em reais), ao migrar para o país de destino, o valor de contribuição transferido seria equivalente a $30 \mathrm{SM}$ (em euros). Esta escolha foi a forma encontrada para tentar minimizar eventuais distorções oriundas de diferenças de renda per capita entre os países. O salário mínimo é uma proxy do que cada sociedade considera como piso necessário para que o indivíduo possa comprar uma cesta de consumo que lhe garanta um nível mínimo de bem-estar. Assim, aos indexar os valores da renda ao salário mínimo, estamos, quando da migração, atrelando de alguma forma o valor de sua renda a este nível mínimo de bem-estar. 


\section{Resultados}

\subsection{Cenário base}

Nesta seção são apresentados os resultados dos cálculos dos indicadores previdenciários descritos na seção 3. Inicialmente reportam-se nas Tabelas 5, 6 e 7 os valores referentes ao Cenário base. Esta é a situação referencial, de um trabalhador que ingressa aos 18 anos de idade no mercado de trabalho e permanece durante toda a sua vida, em cada um dos três países. Os valores mensais de renda e benefício são apresentados para as três faixas de renda inicial (1, 2 e $3 \mathrm{SM}$ ) e para as três taxas de crescimento da renda (1, 2 e 3\%). Para os três países, os valores são apresentados por gênero, dado que as expectativas de sobrevida na data da aposentadoria são diferentes. Com exceção da Taxa de Reposição, todos os indicadores do Brasil são mais elevados, particularmente para mulheres e pessoas de baixa renda. A explicação desta peculiar característica nacional está na regra de cálculo do valor das aposentadorias. Se os(as) contribuintes se aposentam precocemente, não alcançam o requisito da Regra 85/95 e se aposentam pela regra do Fator Previdenciário. Como este é baixo, sua aposentadoria é reduzida, havendo o mesmo efeito sobre a TR. Mas a aposentadoria precoce faz com que o período do recebimento do benefício seja bem maior do que nos demais países, atuando para elevar os valores da TIR e da AliqNec.

Nos três países, a TR é mais elevada para indivíduos com renda inicial mais baixa (embora para Portugal as diferenças sejam mínimas). Há duas explicações para este fato. A primeira explicação é que os sistemas previdenciários têm características redistributivas explícitas, conforme abordado por Gustman e Steinmeier (2001). A segunda explicação, não excludente, é que o valor calculado para as aposentadorias, seguindo as regras de cada país, pode ser menor do que o piso previdenciário, o que obriga a sua elevação. Estes resultados vão ao encontro de achados anteriores de Caetano (2006).

Os valores da Taxa Interna de Retorno (TIR) também são maiores para trabalhadores(as) de renda inicial mais baixa. As TIRs mais elevadas são encontradas para as mulheres do Brasil. Isto ocorre porque estas podem se aposentar cinco anos antes dos homens. Para a Espanha, os valores são mais baixos, havendo diferença mais significativa para a faixa de renda mais elevada. Já para Portugal, os valores são negativos para todos os casos. Este achado deve ser originado principalmente do período contributivo elevado 
(52 anos), conjugado a um tempo de recebimento do benefício reduzido (13,8 anos para os homens e 16,5 anos para as mulheres).

No que se refere à Alíquota Necessária (AliqNec), há clara heterogeneidade entre os países, ainda que seja observado o mesmo padrão, de alíquotas mais elevadas para as faixas de renda mais baixas. Esta é mais uma evidência da redistributividade destes sistemas de previdência. No caso brasileiro, para a maioria das combinações de parâmetros, os valores calculados são superiores às alíquotas efetivamente cobradas. Esta também é uma evidência do desequilíbrio do RGPS. Para a Espanha, os valores obtidos chegam a ser inferiores a um dígito para os trabalhadores de renda e taxa de crescimento mais altas. Finalmente, em Portugal, as alíquotas são bem inferiores àquelas efetivamente cobradas e nota-se que a dispersão dos valores também é menor.

Tabela 5 - Benefício de aposentadoria e indicadores previdenciários - Trabalhadores não migrantes - Brasil

\begin{tabular}{|c|c|c|c|c|c|c|c|c|c|c|c|c|}
\hline \multirow{3}{*}{$\begin{array}{l}\text { Idade } \\
\text { inicial }\end{array}$} & \multirow{3}{*}{$\begin{array}{l}\text { Renda } \\
\text { inicial } \\
\text { (R\$) }\end{array}$} & \multirow{3}{*}{$\begin{array}{c}\text { Taxa de } \\
\text { crescimento } \\
\text { da renda (\%) }\end{array}$} & \multirow{2}{*}{\multicolumn{2}{|c|}{ Idade/TC }} & \multirow{2}{*}{\multicolumn{2}{|c|}{$\begin{array}{l}\text { Aposentadoria } \\
(\mathrm{R} \$)\end{array}$}} & \multicolumn{6}{|c|}{ Indicadores Previdenciários } \\
\hline & & & & & & & \multicolumn{2}{|c|}{ TR (\%) } & \multicolumn{2}{|c|}{$\operatorname{TIR}(\%)$} & \multicolumn{2}{|c|}{ AliqNec (\%) } \\
\hline & & & $\mathrm{H}$ & M & $\mathrm{H}$ & M & $\mathrm{H}$ & M & $\mathrm{H}$ & M & $\mathrm{H}$ & M \\
\hline & 937 & & & & 937 & 937 & 70,65 & 74,25 & 2,68 & 4,15 & 46,09 & 72,39 \\
\hline \multirow[t]{3}{*}{18} & 1.874 & 1 & $53 / 35$ & $48 / 30$ & 1.488 & 1.215 & 56,10 & 48,13 & 1,78 & 2,57 & 36,60 & 46,92 \\
\hline & 2.811 & & & & 2.232 & 1.822 & 56,10 & 48,13 & 1,56 & 2,35 & 36,60 & 46,92 \\
\hline & 937 & & & & 937 & 937 & 50,09 & 55,3 & 2,10 & 3,70 & 28,99 & 46,11 \\
\hline \multirow[t]{3}{*}{18} & 1.874 & 2 & $53 / 35$ & $48 / 30$ & 1.847 & 1.460 & 49,36 & 43,08 & 1,84 & 2,65 & 28,56 & 35,92 \\
\hline & 2.811 & & & & 2.770 & 2.190 & 49,36 & 43,08 & 1,72 & 2,50 & 28,56 & 35,92 \\
\hline & 937 & & & & 1.151 & 937 & 43,75 & 41,30 & 2,17 & 3,17 & 22,60 & 29,78 \\
\hline \multirow[t]{2}{*}{18} & 1.874 & 3 & $53 / 35$ & $48 / 30$ & 2.301 & 1.760 & 43,75 & 38,78 & 1,95 & 2,74 & 22,60 & 27,96 \\
\hline & 2.811 & & & & 3.452 & 2.639 & 43,75 & 38,78 & 1,95 & 2,67 & 22,60 & 27,96 \\
\hline
\end{tabular}

Fonte: Elaboração própria. 
Tabela 6 - Benefício de aposentadoria e indicadores previdenciários - Trabalhadores não migrantes - Espanha

\begin{tabular}{|c|c|c|c|c|c|c|c|c|c|c|c|c|}
\hline \multirow{3}{*}{$\begin{array}{l}\text { Idade } \\
\text { inicial }\end{array}$} & \multirow{3}{*}{$\begin{array}{c}\text { Renda } \\
\text { inicial } \\
(\mathrm{R} \$)\end{array}$} & \multirow{3}{*}{$\begin{array}{c}\text { Taxa de } \\
\text { crescimento } \\
\text { da renda (\%) }\end{array}$} & \multirow{2}{*}{\multicolumn{2}{|c|}{ Idade/TC }} & \multirow{2}{*}{\multicolumn{2}{|c|}{$\begin{array}{c}\text { Aposentadoria } \\
(€)\end{array}$}} & \multicolumn{6}{|c|}{ Indicadores Previdenciários } \\
\hline & & & & & & & \multicolumn{2}{|c|}{$\operatorname{TR}(\%)$} & \multicolumn{2}{|c|}{$\operatorname{TIR}(\%)$} & \multicolumn{2}{|c|}{ AliqNec (\%) } \\
\hline & & & $\mathrm{H}$ & $M$ & $\mathrm{H}$ & $M$ & $\mathrm{H}$ & $M$ & $\mathrm{H}$ & $M$ & $\mathrm{H}$ & $M$ \\
\hline & 825 & & & & 999 & 999 & 75,92 & 75,92 & 0,99 & 1,47 & 28,17 & 33,30 \\
\hline \multirow{3}{*}{18} & 1.650 & 1 & $65 / 47$ & $65 / 47$ & 1.998 & 1.998 & 75,92 & 75,92 & 0,99 & 1,47 & 28,17 & 33,30 \\
\hline & 2.475 & & & & 2.573 & 2.573 & 65,2 & 65,2 & 0,54 & 1,05 & 24,20 & 28,60 \\
\hline & 825 & & & & 1.413 & 1.413 & 67,66 & 67,66 & 1,33 & 1,82 & 22,94 & 26,65 \\
\hline \multirow[t]{3}{*}{18} & 1.650 & 2 & $65 / 47$ & $65 / 47$ & 2.573 & 2.573 & 61,60 & 61,60 & 1,07 & 1,57 & 20,89 & 24,26 \\
\hline & 2.475 & & & & 2.573 & 2.573 & 41,07 & 41,07 & 0,29 & 0,81 & 13,92 & 16,18 \\
\hline & 825 & & & & 2.003 & 2.003 & 60,67 & 60,67 & 1,67 & 2,16 & 18,86 & 21,57 \\
\hline \multirow[t]{2}{*}{18} & 1.650 & 3 & $65 / 47$ & $65 / 47$ & 2.573 & 2.573 & 38,98 & 38,98 & 0,70 & 1,22 & 12,12 & 13,86 \\
\hline & 2.475 & & & & 2.573 & 2.573 & 25,98 & 25,98 & 0,21 & 0,73 & 8,08 & 9,24 \\
\hline
\end{tabular}

Fonte: Elaboração própria.

Tabela 7 - Benefício de aposentadoria e indicadores previdenciários - Trabalhadores não migrantes - Portugal

\begin{tabular}{|c|c|c|c|c|c|c|c|c|c|c|c|c|}
\hline \multirow{3}{*}{$\begin{array}{l}\text { Idade } \\
\text { inicial }\end{array}$} & \multirow{3}{*}{$\begin{array}{c}\text { Renda } \\
\text { inicial (R\$) }\end{array}$} & \multirow{3}{*}{$\begin{array}{c}\text { Taxa de } \\
\text { crescimento } \\
\text { da renda (\%) }\end{array}$} & \multirow{2}{*}{\multicolumn{2}{|c|}{ Idade/TC }} & \multirow{2}{*}{\multicolumn{2}{|c|}{$\begin{array}{c}\text { Aposentadoria } \\
(€)\end{array}$}} & \multicolumn{6}{|c|}{ Indicadores Previdenciários } \\
\hline & & & & & & & \multicolumn{2}{|c|}{ TR $(\%)$} & \multicolumn{2}{|c|}{$\operatorname{IR}(\%)$} & \multicolumn{2}{|c|}{ AliqNec (\%) } \\
\hline & & & $\mathrm{H}$ & M & $\mathrm{H}$ & M & $\mathrm{H}$ & M & $\mathrm{H}$ & M & $\mathrm{H}$ & M \\
\hline & 557 & & & & 751 & 751 & 79,98 & 79,98 & $-0,97$ & $-0,34$ & 18,98 & 22,49 \\
\hline \multirow[t]{3}{*}{18} & 1.114 & 1 & $70 / 52$ & $70 / 52$ & 1.477 & 1.477 & 78,63 & 78,63 & $-1,03$ & $-0,39$ & 18,66 & 22,11 \\
\hline & 1.671 & & & & 2.171 & 2.171 & 77,05 & 77,05 & $-1,1$ & $-0,45$ & 18,29 & 21,66 \\
\hline & 557 & & & & 997 & 997 & 63,32 & 63,32 & $-1,08$ & $-0,39$ & 14,1 & 16,5 \\
\hline \multirow[t]{3}{*}{18} & 1.114 & 2 & $70 / 52$ & $70 / 52$ & 1.948 & 1.948 & 61,83 & 61,83 & $-1,17$ & $-0,47$ & 13,77 & 16,11 \\
\hline & 1.671 & & & & 2.875 & 2.875 & 60,84 & 60,84 & $-1,23$ & $-0,53$ & 13,55 & 15,85 \\
\hline & 557 & & & & 1.351 & 1.351 & 51,37 & 51,37 & $-1,19$ & $-0,44$ & 10,75 & 12,44 \\
\hline \multirow[t]{2}{*}{18} & 1.114 & 3 & $70 / 52$ & $70 / 52$ & 2.622 & 2.622 & 49,86 & 49,86 & $-1,32$ & $-0,55$ & 10,44 & 12,07 \\
\hline & 1.671 & & & & 3.840 & 3.840 & 48,69 & 48,69 & $-1,41$ & $-0,64$ & 10,19 & 11,79 \\
\hline
\end{tabular}

Fonte: Elaboração própria.

\subsection{Migração}

Nesta seção apresentam-se os resultados referentes à migração. Aos 28 anos de idade (10 anos após entrar no mercado de trabalho) o indivíduo migra permanentemente para Espanha ou Portugal. Considera-se inicialmente que a renda inicial no país de destino é igual à última renda no país 
de origem, convertida para múltiplos de salário mínimo. Da mesma forma, supõe-se que a taxa de crescimento salarial é a mesma em ambos os países. As Tabelas 8 e 9 reportam os valores calculados, considerando-se, respectivamente, os fluxos Brasil-Espanha e Brasil-Portugal. Na última coluna é apresentada a variação percentual entre a Contribuição Transferida e a Contribuição Necessária para custear o benefício no país de destino, obtida pela diferença entre os dois termos, dividida pelo segundo.

A Contribuição Transferida, cujo conceito é aqui apresentado, representa, em termos percentuais, o montante de contribuições feitas pelo indivíduo no país de origem e transferido para o país de destino após a migração. Já a Contribuição Necessária representa a soma de contribuições que teriam sido feitas pelo indivíduo durante a vida ativa no país de origem, porém, calculada de acordo com as regras vigentes no país de destino. Desta maneira, os valores calculados na última coluna à direita das Tabelas 8 e 9 são dados pela expressão 9 :

Variação $(\%)=\frac{\text { Contribuição Transferida }- \text { Contribuição Necessária }}{\text { Contribuição Necessária }} .100$

Tabela 8 - Aposentadoria, indicadores previdenciários e variação contributiva Cenário base - Migração Brasil-Espanha aos 28 anos de idade

\begin{tabular}{|c|c|c|c|c|c|c|c|c|c|c|c|}
\hline \multirow{3}{*}{$\begin{array}{l}\text { Renda } \\
\text { inicial } \\
(\mathrm{R} \$)\end{array}$} & \multirow{3}{*}{$\begin{array}{c}\text { Taxa de cresci- } \\
\text { mento da renda } \\
(\%)\end{array}$} & \multirow{3}{*}{$\begin{array}{c}\text { Idade/TC } \\
\text { H/M }\end{array}$} & \multirow{2}{*}{$\begin{array}{c}\text { Aposentadoria } \\
(€)\end{array}$} & \multicolumn{6}{|c|}{ Indicadores Previdenciários } & \multirow{2}{*}{\multicolumn{2}{|c|}{$\begin{array}{c}\text { Variação entre } \\
\text { a contribuição } \\
\text { transferida e } \\
\text { a contribuição } \\
\text { necessária (\%) }\end{array}$}} \\
\hline & & & & \multicolumn{2}{|c|}{ TR (\%) } & \multicolumn{2}{|c|}{$\operatorname{TIR}(\%)$} & \multicolumn{2}{|c|}{ AliqNec (\%) } & & \\
\hline & & & $H / M$ & $\mathrm{H}$ & M & $\mathrm{H}$ & M & $\mathrm{H}$ & M & $\mathrm{H}$ & M \\
\hline 937 & & & 998 & 75,92 & 75,92 & 0,99 & 1,48 & 28,17 & 33,29 & $-1,06$ & $-1,06$ \\
\hline 1.874 & 1 & $65 / 47$ & 1.996 & 75,92 & 75,92 & 0,97 & 1,45 & 28,17 & 33,29 & 2,47 & 2,47 \\
\hline 2.811 & & & 2.573 & 65,25 & 65,25 & 0,48 & 0,99 & 24,21 & 28,62 & 9,54 & 9,54 \\
\hline 937 & & & 1.411 & 67,66 & 67,66 & 1,34 & 1,83 & 22,93 & 26,64 & $-1,06$ & $-1,06$ \\
\hline 1.874 & 2 & $65 / 47$ & 2.573 & 61,70 & 61,70 & 1,06 & 1,56 & 20,91 & 24,29 & 2,47 & 2,47 \\
\hline 2.811 & & & 2.573 & 41,13 & 41,13 & 0,24 & 0,76 & 13,94 & 16,20 & 9,54 & 9,54 \\
\hline 937 & & & 1.998 & 60,67 & 60,67 & 1,67 & 2,16 & 18,85 & 21,56 & $-1,06$ & $-1,06$ \\
\hline 1.874 & 3 & $65 / 47$ & 2.573 & 39,07 & 39,07 & 0,69 & 1,21 & 12,14 & 13,88 & 2,47 & 2,47 \\
\hline 2.811 & & & 2.573 & 26,05 & 26,05 & 0,16 & 0,68 & 8,10 & 9,26 & 9,54 & 9,54 \\
\hline
\end{tabular}

Fonte: Elaboração própria. 
Na Tabela 8 há, na primeira linha, a representação de uma pessoa que ingressou no mercado de trabalho no Brasil aos 18 anos, com renda inicial de 1 SM e taxa de crescimento de $1 \%$ a.a. Aos 28 anos ocorre a migração para Espanha. Para este(a) trabalhador(a) são calculados os três indicadores previdenciários, de forma similar ao apresentado nas Tabelas 5, 6 e 7. No país de origem (Brasil) o montante de contribuições ao longo de toda a vida ativa teria sido de 35,31 SM (contribuição transferida). Se o mesmo estivesse no país de destino (Espanha) - sob as mesmas premissas adotadas no país de origem - teria feito contribuições de 35,69 SM (contribuição necessária). Neste caso, a variação entre a contribuição transferida e a contribuição necessária é de $-1,06 \%$, pois o valor das contribuições efetuadas no país de origem é inferior ao valor de contribuição necessário conforme as regras no país de destino. Uma interpretação deste indicador, consistente com o objetivo do trabalho, é que valores negativos(positivos) correspondem a situações em que, do ponto de vista do trabalhador, levando em consideração o cômputo das contribuições, a migração é vantajosa(desvantajosa) para o indivíduo.

Todos os valores das duas últimas colunas da Tabela 8 são inferiores a $10 \%$, o que pode ser interpretado como uma evidência da semelhança de regras dos sistemas previdenciários. Isto não significa que esta similaridade mostre que o desenho de ambos é adequado, dados os déficits verificados nos trabalhos de Afonso (2018)por alterar parâmetros fundamentais do sistema, como será descrito posteriormente para o caso brasileiro e DíazGimenez e Días-Saavedra (2017) para a Espanha. Como a migração ocorre aos 28 anos e a aposentadoria aos 65 anos, o(a) trabalhador(a) contribui por uma parcela expressiva de sua vida ativa de acordo com as regras previdenciárias da Espanha. Por este motivo, os valores de TR, TIR e AliqNec são bastante similares àqueles apresentados na Tabela 6 .

Na sequência, a Tabela 9 mostra os resultados da migração Brasil-Portugal. Há redução nos valores da TR, TIR e AliqNec em todas as condições, tanto para homens, quanto para mulheres. Os valores negativos reportados nas duas últimas colunas, para o indicador de Variação, são sempre negativos. Neste caso, de forma distinta do verificado para a Espanha, os valores são menores para trabalhadores com níveis de renda mais baixos. 
Ao se comparar a Tabela 8 com as Tabelas 5 e 6 observa-se que, em geral, a TR é mais elevada tanto no caso dos trabalhadores espanhóis, quanto no caso daqueles que migraram do Brasil. Esta observação é particularmente válida para as rendas iniciais mais baixas e com taxas de crescimento menores. No caso de Portugal também é verificado comportamento similar, mas a migração reduz mais a TR do que no caso espanhol, com quedas que chegam a 12 pontos percentuais no caso dos indivíduos de renda mais baixa (1 SM).

Tabela 9 - Aposentadoria, indicadores previdenciários e variação contributiva Cenário base - Migração Brasil-Portugal aos 28 anos de idade

\begin{tabular}{|c|c|c|c|c|c|c|c|c|c|c|c|}
\hline \multirow{3}{*}{$\begin{array}{l}\text { Renda } \\
\text { inicial } \\
\text { ( } R \$)\end{array}$} & \multirow{3}{*}{$\begin{array}{c}\text { Taxa de } \\
\text { crescimento } \\
\text { da renda (\%) }\end{array}$} & \multirow{3}{*}{$\begin{array}{l}\text { Idade/ } \\
\text { TC } \\
\mathrm{H} / \mathrm{M}\end{array}$} & \multirow{3}{*}{$\begin{array}{c}\begin{array}{c}\text { Aposentadoria } \\
(€)\end{array} \\
\\
\\
H / M\end{array}$} & \multicolumn{6}{|c|}{ Indicadores Previdenciários } & \multirow{2}{*}{\multicolumn{2}{|c|}{$\begin{array}{c}\text { Variação entre } \\
\text { a contribuição } \\
\text { transferida e } \\
\text { a contribuição } \\
\text { necessária (\%) }\end{array}$}} \\
\hline & & & & \multicolumn{2}{|c|}{ TR $(\%)$} & \multicolumn{2}{|c|}{$\operatorname{TIR}(\%)$} & \multicolumn{2}{|c|}{$\mathrm{igNec}(\%)$} & & \\
\hline & & & & $\mathrm{H}$ & M & $\mathrm{H}$ & $M$ & $\mathrm{H}$ & $M$ & $\mathrm{H}$ & $M$ \\
\hline 937 & & & 638 & 67,96 & 67,96 & $-1,47$ & $-0,78$ & 16,13 & 19,11 & $-19,42$ & $-19,42$ \\
\hline 1.874 & 1 & $70 / 52$ & 1.255 & 66,88 & 66,88 & $-1,54$ & $-0,85$ & 15,87 & 18,80 & $-16,55$ & $-16,55$ \\
\hline 2.811 & & & 1.853 & 65,83 & 65,83 & $-1,62$ & $-0,92$ & 15,62 & 18,51 & $-10,79$ & $-10,79$ \\
\hline 937 & & & 880 & 55,96 & 55,96 & $-1,49$ & $-0,75$ & 12,46 & 14,58 & $-19,42$ & $-19,42$ \\
\hline 1.874 & 2 & $70 / 52$ & 1.724 & 54,80 & 54,80 & $-1,58$ & $-0,84$ & 12,20 & 14,27 & $-16,55$ & $-16,55$ \\
\hline 2.811 & & & 2.539 & 53,81 & 53,81 & $-1,67$ & $-0,92$ & 11,98 & 14,02 & $-10,79$ & $-10,79$ \\
\hline 937 & & & 1.226 & 46,73 & 46,73 & $-1,54$ & $-0,74$ & 9,78 & 11,31 & $-19,42$ & $-19,42$ \\
\hline 1.874 & 3 & $70 / 52$ & 2.383 & 45,44 & 45,44 & $-1,66$ & $-0,86$ & 9,51 & 11,00 & $-16,55$ & $-16,55$ \\
\hline 2.811 & & & 3.499 & 44,48 & 44,48 & $-1,77$ & $-0,96$ & 9,31 & 10,77 & $-10,79$ & $-10,79$ \\
\hline
\end{tabular}

Fonte: Elaboração própria.

\subsection{Extensões}

Nesta seção, empregando-se a mesma metodologia descrita anteriormente, fazem-se algumas extensões, com a alteração de algumas premissas.

\subsubsection{Migração aos 38 anos de idade}

A primeira extensão é a elevação da idade de migração, que passa dos 28 para os 38 anos de idade, ou seja, 20 anos após a entrada no mercado de trabalho. As Tabelas 10 e 11 trazem estes resultados. Estes podem ser comparados, respectivamente, com as Tabelas 8 e 9, para que se comparem os efeitos desta postergação na migração. 
Tabela 10 - Aposentadoria, indicadores previdenciários e variação contributiva Migração aos 38 anos Brasil-Espanha

\begin{tabular}{|c|c|c|c|c|c|c|c|c|c|c|c|}
\hline \multirow{3}{*}{$\begin{array}{c}\text { Renda } \\
\text { inicial } \\
(\mathrm{R} \$)\end{array}$} & \multirow{3}{*}{$\begin{array}{c}\text { Taxa de } \\
\text { crescimento } \\
\text { da renda (\%) }\end{array}$} & \multirow{3}{*}{$\begin{array}{c}\text { Idade/TC } \\
\text { H/M }\end{array}$} & \multirow{3}{*}{$\begin{array}{c}\begin{array}{c}\text { Aposentadoria } \\
(\mathrm{R} \$)\end{array} \\
\mathrm{H} / \mathrm{M}\end{array}$} & \multicolumn{6}{|c|}{ Indicadores Previdenciários } & \multirow{2}{*}{\multicolumn{2}{|c|}{$\begin{array}{c}\text { Variação entre } \\
\text { a contribuição } \\
\text { transferida e } \\
\text { a contribuição } \\
\text { necessária (\%) }\end{array}$}} \\
\hline & & & & \multicolumn{2}{|c|}{ TR (\%) } & \multicolumn{2}{|c|}{$\operatorname{TIR}(\%)$} & \multicolumn{2}{|c|}{ AliqNec (\%) } & & \\
\hline & & & & $\mathrm{H}$ & M & $\mathrm{H}$ & M & $\mathrm{H}$ & M & $\mathrm{H}$ & M \\
\hline 937 & & & 998 & 75,92 & 75,92 & 1,00 & 1,48 & 28,16 & 33,29 & $-1,06$ & $-1,06$ \\
\hline 1.874 & 1 & $65 / 47$ & 1.996 & 75,92 & 75,92 & 0,95 & 1,44 & 28,16 & 33,29 & 2,47 & 2,47 \\
\hline 2.811 & & & 2.573 & 65,25 & 65,25 & 0,42 & 0,94 & 24,21 & 28,61 & 9,54 & 9,54 \\
\hline 937 & & & 1.411 & 67,66 & 67,66 & 1,34 & 1,83 & 22,92 & 26,63 & $-1,06$ & $-1,06$ \\
\hline 1.874 & 2 & $65 / 47$ & 2.573 & 61,70 & 61,70 & 1,04 & 1,54 & 20,91 & 24,29 & 2,62 & 2,62 \\
\hline 2.811 & & & 2.573 & 41,13 & 41,13 & 0,17 & 0,70 & 13,94 & 16,19 & 9,55 & 9,55 \\
\hline 937 & & & 1.998 & 60,67 & 60,67 & 1,68 & 2,17 & 18,84 & 21,55 & $-0,92$ & $-0,92$ \\
\hline 1.874 & 3 & $65 / 47$ & 2.573 & 39,07 & 39,07 & 0,64 & 1,17 & 12,14 & 13,88 & 5,34 & 5,34 \\
\hline 2.811 & & & 2.573 & 26,05 & 26,05 & 0,04 & 0,57 & 8,09 & 9,25 & 14,18 & 14,18 \\
\hline
\end{tabular}

Fonte: Elaboração própria.

Tabela 11 - Aposentadoria, indicadores previdenciários e variação contributiva Migração aos 38 anos Brasil-Portugal

\begin{tabular}{|c|c|c|c|c|c|c|c|c|c|c|c|}
\hline \multirow{3}{*}{$\begin{array}{c}\text { Renda } \\
\text { inicial (R\$) }\end{array}$} & \multirow{3}{*}{$\begin{array}{l}\text { Taxa de cres- } \\
\text { cimento da } \\
\text { renda (\%) }\end{array}$} & \multirow{3}{*}{$\begin{array}{c}\text { Idade/TC } \\
\text { H/M }\end{array}$} & \multirow{3}{*}{$\begin{array}{c}\begin{array}{c}\text { Aposentadoria } \\
(\mathrm{R} \$)\end{array} \\
\\
\\
\mathrm{H} / \mathrm{M}\end{array}$} & \multicolumn{6}{|c|}{ Indicadores Previdenciários } & \multirow{2}{*}{\multicolumn{2}{|c|}{$\begin{array}{c}\text { Variação entre } \\
\text { a contribuição } \\
\text { transferida e } \\
\text { a contribuição } \\
\text { necessária (\%) }\end{array}$}} \\
\hline & & & & \multicolumn{2}{|c|}{ TR $(\%)$} & \multicolumn{2}{|c|}{$\operatorname{TIR}(\%)$} & \multicolumn{2}{|c|}{ AliqNec (\%) } & & \\
\hline & & & & $\mathrm{H}$ & M & $\mathrm{H}$ & M & $\mathrm{H}$ & M & $\mathrm{H}$ & M \\
\hline 937 & & & 511 & 54,50 & 54,50 & $-2,20$ & $-1,44$ & 12,93 & 15,32 & $-19,42$ & $-19,42$ \\
\hline 1.874 & 1 & $70 / 52$ & 1.007 & 53,63 & 53,63 & $-2,29$ & $-1,52$ & 12,73 & 15,08 & $-16,55$ & $-16,55$ \\
\hline 2.811 & & & 1.487 & 52,82 & 52,82 & $-2,39$ & $-1,62$ & 12,53 & 14,85 & $-10,79$ & $-10,79$ \\
\hline 937 & & & 734 & 46,67 & 46,67 & $-2,14$ & $-1,33$ & 10,38 & 12,15 & $-19,42$ & $-19,42$ \\
\hline 1.874 & 2 & $70 / 52$ & 1.437 & 45,68 & 45,68 & $-2,25$ & $-1,43$ & 10,16 & 11,89 & $-16,43$ & $-16,43$ \\
\hline 2.811 & & & 2.117 & 44,87 & 44,87 & $-2,36$ & $-1,54$ & 9,98 & 11,68 & $-10,79$ & $-10,79$ \\
\hline 937 & & & 1.057 & 40,30 & 40,30 & $-2,10$ & $-1,24$ & 8,43 & 9,75 & $-19,31$ & $-19,31$ \\
\hline 1.874 & 3 & $70 / 52$ & 2.054 & 39,15 & 39,15 & $-2,26$ & $-1,39$ & 8,19 & 9,47 & $-14,21$ & $-14,21$ \\
\hline 2.811 & & & 3.011 & 38,27 & 38,27 & $-2,38$ & $-1,50$ & 8,00 & 9,26 & $-10,79$ & $-10,79$ \\
\hline
\end{tabular}

Fonte: Elaboração própria.

Em relação aos resultados do fluxo migratório Brasil-Espanha, apresentados nas Tabelas 8 e 10, nota-se que há pouca sensibilidade do valor da aposentadoria. Em particular, isso ocorre porque a alíquota somada no Brasil (28 
a 31\%) é muito similar à verificada na Espanha (28\%). Há pequena redução nos valores da $T I R$, mais expressiva para as rendas mais altas.

Ao comparar as Tabelas 9 e 11 (migração para Portugal), a postergação da migração provoca redução no valor da aposentadoria para todos os casos. Por exemplo, para o indivíduo com renda inicial de 1 SM e taxa de crescimento salarial de $1 \%$ que migra aos 28 anos de idade, o valor da aposentadoria seria de $€ 638$. Porém, ao postergar a migração para os 38 anos de idade, o benefício assume o valor de $€ 511$. Como decorrência, todos os valores dos indicadores sofrem redução da ordem de 17pontos percentuais para a TR e para a AliqNec. Já a TIR média tem redução mais expressiva, de $-1,22 \%$ para $-1,85 \%$.

\subsubsection{Renda diferente no país de destino (50\% maior ou $50 \%$ menor)}

No Cenário base e na seção 4.3.1, não há mudança de renda quando da migração. Como esta é uma premissa relativamente forte, é alterada nesta seção.

Nas Tabelas 12 e 13 apresentam-se os resultados quando a renda no país de destino é 50\% maior em relação à última renda no país de origem. Em ambos os casos (Brasil-Espanha e Brasil-Portugal) como seria esperado, há aumento nos benefícios. No caso espanhol, há um valor máximo de aposentadoria, de $€ 2.573,70$, que limita os valores da aposentadoria em cinco casos. Como resultado, a TR cai nestes casos, comparando-se as Tabelas 8 e 12. Já a TIR aumenta em todas as situações, mas o incremento é menor quando o valor do benefício foi limitado ao teto. Para AliqNec, sempre é observada redução, sendo esta mais significativa para as faixas de renda mais alta. No caso de Portugal, nota-se mudança marginal na TR e pequenas reduções na TIR e AliqNec. Porém, estas reduções são bem menores do que foi encontrado para a Espanha. Cabe assinalar que tanto para Espanha, quanto para Portugal, não há mudanças para a Contribuição Transferida. Isso ocorre, pois esta é calculada tendo como base o período e o montante contribuído no país. Dado que somente houve mudanças após a migração, o período anterior à mudança de país não foi afetado. 
Na sequência, as Tabelas 14 e 15 mostram os efeitos de uma queda de $50 \%$ na renda quando da migração. Conforme o esperado, há redução no montante do benefício em ambos os países. Na mudança para a Espanha, comparativamente ao cenário base, não há efeitos sobre a $T R$, a não ser nas situações em que o valor do teto era atingido. Para a $T I R$, o valor aumenta somente para a faixa de renda mais baixa, devido ao piso, e observa-se pequena redução para os demais grupos. Para AliqNec, a redução é menos expressiva, a não ser nas faixas de renda mais elevadas e com maio crescimento. Na mudança para Portugal com redução na renda, a TIR praticamente não se altera. A TIR aumenta apenas para o grupo mais pobre (primeira linha da tabela) e reduz para todos os demais, ainda que esta queda não seja tão expressiva e reduza-se para os grupos de renda mais alta. Para AliqNec, observa-se fenômeno oposto, com aumento na alíquota para os indivíduos de renda mais baixa e redução para todos os demais.

Tabela 12 - Aumento de 50\% na renda no país de destino - Migração Brasil-Espanha

\begin{tabular}{|c|c|c|c|c|c|c|c|c|c|c|c|}
\hline \multirow{3}{*}{$\begin{array}{c}\text { Renda } \\
\text { inicial } \\
(\mathrm{R} \$)\end{array}$} & \multirow{3}{*}{$\begin{array}{l}\text { Taxa de } \\
\text { crescimento } \\
\text { da renda } \\
(\%)\end{array}$} & \multirow{3}{*}{$\begin{array}{c}\text { Idade/TC } \\
\text { H/M }\end{array}$} & \multirow{3}{*}{$\begin{array}{c}\text { Aposentadoria } \\
(\mathrm{R} \$)\end{array}$} & \multicolumn{6}{|c|}{ Indicadores Previdenciários } & \multirow{2}{*}{\multicolumn{2}{|c|}{$\begin{array}{l}\text { Variação entre } \\
\text { a contribuição } \\
\text { transferida e } \\
\text { a contribuição } \\
\text { necessária (\%) }\end{array}$}} \\
\hline & & & & \multicolumn{2}{|c|}{ TR $(\%)$} & \multicolumn{2}{|c|}{$\operatorname{TIR}(\%)$} & \multicolumn{2}{|c|}{ AliqNec (\%) } & & \\
\hline & & & & $\mathrm{H}$ & M & $\mathrm{H}$ & $M$ & $\mathrm{H}$ & M & $\mathrm{H}$ & M \\
\hline 937 & & & 1497 & 75,92 & 75,92 & 1,23 & 1,72 & 30,32 & 35,84 & $-1,06$ & $-1,06$ \\
\hline 1.874 & 1 & $65 / 47$ & 2.573 & 65,25 & 65,25 & 0,75 & 1,27 & 26,06 & 30,80 & 2,47 & 2,47 \\
\hline 2.811 & & & 2.573 & 43,50 & 43,50 & 0,20 & 0,73 & 17,37 & 20,54 & 9,54 & 9,54 \\
\hline 937 & & & 2.117 & 67,66 & 67,66 & 1,55 & 2,05 & 24,69 & 28,68 & $-1,06$ & $-1,06$ \\
\hline 1.874 & 2 & $65 / 47$ & 2.573 & 41,13 & 41,13 & 0,48 & 1,01 & 15,01 & 17,43 & 2,47 & 2,47 \\
\hline 2.811 & & & 2.573 & 27,42 & 27,42 & 0,17 & 0,70 & 10,01 & 11,62 & 9,54 & 9,54 \\
\hline 937 & & & 2.573 & 52,10 & 52,10 & 1,49 & 2,00 & 17,43 & 19,93 & $-1,06$ & $-1,06$ \\
\hline 1.874 & 3 & $65 / 47$ & 2.573 & 26,05 & 26,05 & 0,40 & 0,93 & 8,71 & 9,96 & 2,47 & 2,47 \\
\hline 2.811 & & & 2.573 & 17,37 & 17,37 & 0,15 & 0,67 & 5,81 & 6,64 & 9,54 & 9,54 \\
\hline
\end{tabular}

Fonte: Elaboração própria. 
Tabela 13 - Redução de 50\% na renda no país de destino - Migração Brasil-Portugal

\begin{tabular}{|c|c|c|c|c|c|c|c|c|c|c|c|}
\hline \multirow{3}{*}{$\begin{array}{l}\text { Renda } \\
\text { inicial } \\
(\mathrm{R} \$)\end{array}$} & \multirow{3}{*}{$\begin{array}{c}\text { Taxa de } \\
\text { crescimento } \\
\text { da renda (\%) }\end{array}$} & \multirow{3}{*}{$\begin{array}{c}\text { Idade/TC } \\
\text { H/M }\end{array}$} & \multirow{3}{*}{$\begin{array}{c}\begin{array}{c}\text { Aposentadoria } \\
(\mathrm{R} \$)\end{array} \\
\mathrm{H} / \mathrm{M}\end{array}$} & \multicolumn{6}{|c|}{ Indicadores Previdenciários } & \multirow{2}{*}{\multicolumn{2}{|c|}{$\begin{array}{c}\text { Variação entre } \\
\text { a contribuição } \\
\text { transferida e } \\
\text { a contribuição } \\
\text { necessária (\%) }\end{array}$}} \\
\hline & & & & \multicolumn{2}{|c|}{$\operatorname{TR}(\%)$} & \multicolumn{2}{|c|}{$\operatorname{TIR}(\%)$} & \multicolumn{2}{|c|}{ AliqNec (\%) } & & \\
\hline & & & & $\mathrm{H}$ & M & $\mathrm{H}$ & M & $\mathrm{H}$ & M & $\mathrm{H}$ & M \\
\hline 937 & & & 948 & 67,34 & 67,34 & $-1,39$ & $-0,69$ & 17,06 & 20,21 & $-19,42$ & $-19,42$ \\
\hline 1.874 & 1 & $70 / 52$ & 1.853 & 65,83 & 65,83 & $-1,49$ & $-0,78$ & 16,68 & 19,76 & $-16,55$ & $-16,55$ \\
\hline 2.811 & & & 2.733 & 64,72 & 64,72 & $-1,57$ & $-0,85$ & 16,40 & 19,43 & $-10,79$ & $-10,79$ \\
\hline 937 & & & 1.307 & 55,40 & 55,40 & $-1,44$ & $-0,69$ & 13,17 & 15,41 & $-19,42$ & $-19,42$ \\
\hline 1.874 & 2 & $70 / 52$ & 2.539 & 53,81 & 53,81 & $-1,57$ & $-0,80$ & 12,79 & 14,97 & $-16,55$ & $-16,55$ \\
\hline 2.811 & & & 3.722 & 52,59 & 52,59 & $-1,67$ & $-0,90$ & 12,50 & $-10,79$ & $-10,79$ & $-10,79$ \\
\hline 937 & & & 1.811 & 46,03 & 46,03 & $-1,53$ & $-0,72$ & 10,28 & 11,90 & $-19,42$ & $-19,42$ \\
\hline 1.874 & 3 & $70 / 52$ & 3.499 & 44,48 & 44,48 & $-1,69$ & $-0,86$ & 9,94 & 11,50 & $-16,55$ & $-16,55$ \\
\hline 2.811 & & & 5.135 & 43,51 & 43,51 & $-1,79$ & $-0,96$ & 9,72 & 11,25 & $-10,79$ & $-10,79$ \\
\hline
\end{tabular}

Fonte: Elaboração própria.

Tabela 14 - Redução de 50\% na renda no país de destino - Migração Brasil-Espanha

\begin{tabular}{|c|c|c|c|c|c|c|c|c|c|c|c|}
\hline \multirow{3}{*}{$\begin{array}{c}\text { Renda } \\
\text { inicial } \\
\text { (R\$) }\end{array}$} & \multirow{3}{*}{$\begin{array}{c}\text { Taxa de } \\
\text { crescimento da } \\
\text { renda (\%) }\end{array}$} & \multirow{3}{*}{$\begin{array}{c}\text { Idade/TC } \\
\text { H/M }\end{array}$} & \multirow{3}{*}{$\begin{array}{c}\begin{array}{c}\text { Aposentadori } \\
(\mathrm{R} \$)\end{array} \\
\mathrm{H} / \mathrm{M}\end{array}$} & \multicolumn{6}{|c|}{ Indicadores Previdenciários } & \multirow{2}{*}{\multicolumn{2}{|c|}{$\begin{array}{l}\text { Variação entre } \\
\text { a contribuição } \\
\text { transferida e } \\
\text { a contribuição } \\
\text { necessária (\% }\end{array}$}} \\
\hline & & & & \multicolumn{2}{|c|}{$\operatorname{TR}(\%)$} & \multicolumn{2}{|c|}{$\operatorname{TIR}(\%)$} & \multicolumn{2}{|c|}{ AliqNec (\%) } & & \\
\hline & & & & $\mathrm{H}$ & M & $\mathrm{H}$ & M & $\mathrm{H}$ & M & $\mathrm{H}$ & M \\
\hline 937 & & & 904 & 75,92 & 75,92 & 1,14 & 1,58 & 29,68 & 35,08 & $-1,06$ & $-1,06$ \\
\hline 1.874 & 1 & $65 / 47$ & 998 & 75,92 & 75,92 & 0,42 & 0,90 & 23,22 & 27,45 & 2,47 & 2,47 \\
\hline 2.811 & & & 1.497 & 75,92 & 75,92 & 0,35 & 0,83 & 23,22 & 27,45 & 9,54 & 9,54 \\
\hline 937 & & & 1.160 & 67,66 & 67,66 & 0,83 & 1,31 & 18,91 & 21,96 & $-1,06$ & $-1,06$ \\
\hline 1.874 & 2 & $65 / 47$ & 1.411 & 67,66 & 67,66 & 0,8 & 1,28 & 18,91 & 21,96 & 2,47 & 2,47 \\
\hline 2.811 & & & 2.117 & 67,66 & 67,66 & 0,74 & 1,22 & 18,91 & 21,96 & 9,54 & 9,54 \\
\hline 937 & & & 1.490 & 60,67 & 60,67 & 1,20 & 1,68 & 15,54 & 17,77 & $-1,06$ & $-1,06$ \\
\hline 1.874 & 3 & $65 / 47$ & 1.998 & 60,67 & 60,67 & 1,17 & 1,66 & 15,54 & 17,77 & 2,47 & 2,47 \\
\hline 2.811 & & & 2.573 & 52,10 & 52,10 & 0,77 & 1,26 & 13,35 & 15,26 & 9,54 & 9,54 \\
\hline
\end{tabular}

Fonte: Elaboração própria. 
Tabela 15 - Redução de 50\% na renda no país de destino - Migração Brasil-Portugal

\begin{tabular}{|c|c|c|c|c|c|c|c|c|c|c|c|}
\hline \multirow{3}{*}{$\begin{array}{c}\text { Renda } \\
\text { inicial } \\
(\mathrm{R} \$)\end{array}$} & \multirow{3}{*}{$\begin{array}{c}\text { Taxa de } \\
\text { crescimento } \\
\text { da renda (\%) }\end{array}$} & \multirow{3}{*}{$\begin{array}{c}\text { Idade/TC } \\
\text { H/M }\end{array}$} & \multirow{3}{*}{$\begin{array}{c}\text { Aposentadoria } \\
(\mathrm{R} \$) \\
\\
\mathrm{H} / \mathrm{M} \\
\end{array}$} & \multicolumn{6}{|c|}{ Indicadores Previdenciários } & \multirow{2}{*}{\multicolumn{2}{|c|}{$\begin{array}{c}\text { Variação entre a } \\
\text { contribuição } \\
\text { transferida e a } \\
\text { contribuição } \\
\text { necessária (\%) }\end{array}$}} \\
\hline & & & & \multicolumn{2}{|c|}{$\operatorname{TR}(\%)$} & \multicolumn{2}{|c|}{$\operatorname{TIR}(\%)$} & \multicolumn{2}{|c|}{ AliqNec (\%) } & & \\
\hline & & & & $\mathrm{H}$ & $M$ & $\mathrm{H}$ & M & $\mathrm{H}$ & $M$ & $\mathrm{H}$ & $M$ \\
\hline 937 & & & 948 & 68,06 & 68,06 & $-1,14$ & $-0,53$ & 16,25 & 19,25 & $-19,42$ & $-19,42$ \\
\hline 1.874 & 1 & $70 / 52$ & 1.853 & 67,96 & 67,96 & $-1,77$ & $-1,11$ & 13,55 & 16,05 & $-16,55$ & $-16,55$ \\
\hline 2.811 & & & 2.733 & 67,34 & 67,34 & $-1,84$ & $-1,17$ & 13,43 & 15,90 & $-10,79$ & $-10,79$ \\
\hline 937 & & & 1.307 & 56,25 & 56,25 & $-1,67$ & $-0,97$ & 10,60 & 12,41 & $-19,42$ & $-19,42$ \\
\hline 1.874 & 2 & $70 / 52$ & 2.539 & 55,96 & 55,96 & $-1,74$ & $-1,03$ & 10,46 & 12,24 & $-16,55$ & $-16,55$ \\
\hline 2.811 & & & 3.722 & 55,40 & 55,40 & $-1,80$ & $-1,09$ & 10,36 & 12,12 & $-10,75$ & $-10,75$ \\
\hline 937 & & & 1.811 & 47,07 & 47,07 & $-1,66$ & $-0,90$ & 8,34 & 9,65 & $-19,42$ & $-19,42$ \\
\hline 1.874 & 3 & $70 / 52$ & 3.499 & 46,73 & 46,73 & $-1,74$ & $-0,97$ & 8,21 & 9,50 & $-16,55$ & $-16,55$ \\
\hline 2.811 & & & 5.135 & 46,03 & 46,03 & $-1,82$ & $-1,05$ & 8,09 & 9,36 & $-10,79$ & $-10,79$ \\
\hline
\end{tabular}

Fonte: Elaboração própria.

\section{Considerações finais}

Este trabalho procurou avaliar quantitativamente os impactos decorrentes das migrações para os indivíduos, por meio de indicadores previdenciários. Buscou-se explorar uma lacuna na literatura, que até o momento tem focado em questões mais conceituais, ligadas ao arcabouço da proteção social, ou aos aspectos jurídicos inerentes ao reconhecimento do período contributivo. Foram analisados os casos da migração once-for-all do Brasil para a Espanha e para Portugal. O trabalho encontra-se embasado na construção de indicadores previdenciários e na literatura sobre migrações. Em particular, segue-se a linha baseada na fundamentação microeconômica originada de Becker (1975), Sjaastad 1962 e Todaro (1969), adicionando-se aos custos e benefícios marginais da migração, as eventuais variações no valor do benefício de aposentadoria e dos demais indicadores previdenciários.

A migração durante a vida ativa, tanto para Espanha quanto para Portugal, gera aumento no valor do benefício de aposentadoria do indivíduo, comparativamente à situação de permanência a vida inteira no Brasil, tanto para homens, quanto para mulheres. A Taxa de Reposição (TR) é maior para o 
fluxo Brasil-Espanha, ou seja, a redução na renda real do trabalhador após a aposentadoria é menor quando este migra para a Espanha, ao invés de permanecer no Brasil. A exceção são os trabalhadores de renda mais alta, que atingem o teto previdenciário. Entretanto, conforme mostra a literatura (Clingman, Burkhalter, e Chaplain 2014; Quinn 1999) a TR é um indicador imperfeito. Por este motivo, outros indicadores, que levem em conta os aspectos intertemporais devem ser analisados conjuntamente. A Taxa Interna de Retorno (TIR) é menor na migração para qualquer país, comparativamente ao verificado no Brasil, pouco se altera no caso espanhol e diminui no caso português (comparativamente aos trabalhadores que passaram toda a sua vida ativa nestes países). De forma geral, os valores das Alíquotas Necessárias (AliqNec) são decrescentes com a renda para todos os países, sendo inferiores às alíquotas efetivamente cobradas para os níveis de renda mais elevados.

Para captar os efeitos da migração sobre a previdência, propôs-se a criação de um indicador de variação entre a contribuição transferida e a contribuição necessária. Ou seja, a variação entre o montante das contribuições efetuadas no país de origem e valor necessário durante este mesmo período conforme a alíquota vigente no país de destino, para custear o benefício. Foram obtidos resultados distintos. Na Espanha, os valores são negativos para a menor taxa de crescimento da renda, e positivos nos outros casos. Já para Portugal, o indicador é negativo em todas as situações analisadas.

Foram realizadas duas modificações nas premissas adotadas no cenário base: alteração da idade de migração (de 28 anos de idade para 38 anos de idade) e alteração da variação da renda inicial no país de destino (de $0 \%$ para $-50 \%$ e $+50 \%)$. Os resultados apresentaram sensibilidade do valor da aposentadoria e dos indicadores previdenciários à alteração na variação da renda inicial no país de destino. Também é relevante a taxa de crescimento da renda. Isto significa que há heterogeneidade nos efeitos, de acordo com os indivíduos representativos analisados.

Cabe lembrar que todos os cálculos do artigo foram feitos com as regras que prevaleciam antes da promulgação da Emenda Constitucional 103, em novembro de 2019. Esta reforma previdenciária, implantada no primeiro ano governo de Jair Bolsonaro alterou a fórmula de cálculo dos benefícios programáveis, aumentou as idades mínimas de aposentadoria e alterou as alíquotas contributivas. Estas mudanças devem afetar os resultados aqui reportados. 
Pode se considerar que este trabalho aborda aspectos quantitativos pouco explorados na interface das literaturas sobre previdência e sobre migração. Em particular, imagina-se que tenha sido apresentada uma inovação, com o indicador de variação contributiva decorrente da migração. Parece razoável inferir que os resultados vão ao encontro da argumentação de Lee (1966) e Massey et al. (1993), no sentido de que os fatores econômicos podem desempenhar papel importante, mas ainda pouco estudado, para a migração. Neste caso, indivíduos racionais poderiam levar em conta não somente a renda do trabalho, mas também os benefícios de aposentadoria. Considerase que tais resultados possam ajudar fornecer subsídios para as políticas migratórias e de proteção social. Possivelmente, trabalhos futuros possam ampliar estes horizontes incorporando mais países ou também detalhando os motivos para migração, como o diferencial na qualidade dos serviços públicos. Outra possibilidade seria a expansão da unidade de decisão para a família, na linha da argumentação de Massey et al. (1998), o que levaria à incorporação de outros benefícios, como as pensões por morte, tema relevante na literatura sobre previdência social.

\section{Referências}

Afonso, Luís Eduardo. 2016. "Progressividade e Aspectos Distributivos Na Previdência Social: Uma Análise Com o Emprego Dos Microdados Dos Registros Administrativos Do RGPS." Revista Brasileira de Economia 70, no.1: 3-30. https://doi.org/10.5935/0034-7140.20160001.

Afonso, Luís Eduardo. 2018. "Reforma Temer: Os Impactos Da PEC 287/2016 Sobre o RGPS." In Desafios Da Nação: Artigos de Apoio, v. 2, editado por João Alberto de Negri, Bruno César Araújo, e Ricardo Bacelette, 253-84. Brasília: IPEA. http://www.ipea.gov.br/portal/images/stories/PDFs/livros/livros/180413_desafios_da_nacao_artigos_vol2_cap23.pdf.

Alves, José, Daniela Craveiro, Maria Teresa Medeiros Garcia, e Paula Albuquerque. 2019. “The Impact of International Migration on the Public Pension System: The Case of Portugal." International Social Security Review 72, no.1: 107-28. https://doi.org/10.1111/issr.12197.

Avato, Johanna, Johannes Koettl, e Rachel Sabates-Wheeler. 2010. "Social Security Regimes, Global Estimates, and Good Practices: The Status of Social Protection for International Migrants." World Development 38, no.4: 455-66. https://doi.org/10.1016/j.worlddev.2009.10.003.

Barr, Nicholas, e Peter Diamond. 2006. "The Economics of Pensions." Oxford Review of Economic Policy 22, no.1: 15-39. https://doi.org/10.1093/oxrep/grj002.

Becker, Gary S. 1975. Human Capital: A Theoretical and Empirical Analysis, with Special Reference to Education. 2nd ed. New York: Columbia University Press. http://papers.nber.org/books/beck75-1.

Bodvarsson, Örn B., e Hendrik Van den Berg. 2013. "The Determinants of International Migration: Theory." In The Economics of Immigration 27-57. New York, NY: Springer New York. https://doi.org/10.1007/978-14614-2116-0_2. 
Borjas, George J. 1999. "The Economic Analysis of Immigration.” In Handbook of Labor Economics 3 Part A:1697-1760. Amsterdam: Elsevier Masson SAS. https://doi.org/10.1016/S1573-4463(99)03009-6.

Bridges, Benjamin, e Sharmila Choudhury. 2007. "Social Security as a Retirement Resource for Near-Retirees, by Race and Ethnicity, Nativity, Benefit Type, and Disability Status." ORES Working Paper Series 109. Washington, D.C. https://www.ssa.gov/policy/docs/workingpapers/wp109.html.

Caetano, Marcelo Abi-Ramia. 2006. "Subsídios Cruzados Na Previdência Social Brasileira." Texto Para Discussão - IPEA 1211. Brasília. http://www.ipea.gov.br/portal/images/stories/PDFs/TDs/td_1211.pdf.

Campos, Marden Barbosa De. 2015. "Seletividade e Migração.” In População, Espaço e Sustentabilidade: Contribuições Para o Desenvolvimento Do Brasil, editado por Miguel Bruno, 187-202. Rio de Janeiro: Instituto Brasileiro de Geografia e Estatística. https://biblioteca.ibge.gov.br/visualizacao/livros/liv94508.pdf.

Clingman, Michael, Kyle Burkhalter, e Chris Chaplain. 2014. "Internal Real Rates of Return under the OASDI Program for Hypothetical Workers." Actuarial Note 2014.5. Baltimore, Maryland. https://www.ssa.gov/OACT/ NOTES/ran5/an2014-5.pdf.

Clingman, Michael, Kyle Burkhalter, e Chris Chaplain. 2019. "Internal Real Rates of Return under the OASDI Program for Hypothetical Workers." Actuarial Note 2018.5. Baltimore, Maryland. https://www.ssa.gov/OACT/ NOTES/ran5/an2018-5.pdf.

Cohen, Lee, e Howard Iams. 2007. "Income Adequacy and Social Security Differences between the Foreign-Born and U.S.-Born." International Migration Review 41, no.3: 553-78. https://doi.org/10.1111/j. 1747-7379.2007.00085.x.

Collado, M. Dolores, Iñigo Iturbe-Ormaetxe, e Guadalupe Valera. 2004. "Quantifying the Impact of Immigration on the Spanish Welfare State." International Tax and Public Finance 11, no.3: 335-53. https://doi.org/10.1023/B:ITAX.0000021975.20256.ff.

Couch, Kenneth A., Gayle L. Reznik, Christopher R. Tamborini, e Howard M. Iams. 2017. "The Distributional Impact of Social Security Policy Options." Research on Aging 39, no.1: 135-65. https://doi. org/10.1177/0164027516656140.

Czaika, Mathias, e Hein de Haas. 2014. "The Globalization of Migration: Has the World Become More Migratory?” International Migration Review 48, no.2: 283-323. https://doi.org/10.1111/imre.12095.

Díaz-Gimenez, Javier, e Julián Díaz-Saavedra. 2017. "The Future of Spanish Pensions.” Journal of Pension Economics and Finance 16, no.02: 233-65. https://doi.org/10.1017/S1474747216000093.

Direção-Geral da Segurança Social (DGSS). 2020. "Código Dos Regimes Contributivos Do Sistema Previdencial de Segurança Social: Redação Em Vigor.” Lisboa: Instituto de Segurança Social. http://www.seg-social.pt/ documents/10152/15009350/Código contributivo - redação em vigor/1e56fad5-0e2a-42c2-b94c-194c4aa64f74.

Dixon, John. 1998. “Comparative Social Security: The Challenge of Evaluation.” Journal of Comparative Policy Analysis: Research and Practice 1, no.1: 61-95. https://doi.org/10.1080/13876989808412616.

Docquier, Frédéric, e Luca Marchiori. 2012. "The Impact of MENA-to-EU Migration in the Context of Demographic Change." Journal of Pension Economics and Finance 11, no.2: 243-84. https://doi.org/10.1017/ S147474721100028X.

Fenge, Robert, e François Peglow. 2018. "Decomposition of Demographic Effects on the German Pension System." Journal of the Economics of Ageing 12 (February): 61-76. https://doi.org/10.1016/j.jeoa.2018.01.001.

Fornalé, Elisa. 2017. "Global-Regional Interaction to Extend Access to Social Protection for Migrant Workers: Insights from ASEAN and MERCOSUR.” International Social Security Review 70, no.3: 31-52. https://doi. org/10.1111/issr.12140.

Forteza, Alvaro. 2010. "The Portability of Pension Rights: General Principles and the Caribbean Case." Development Policy Review 28, no.2: 237-55. https://doi.org/10.1111/j.1467-7679.2010.00483.x.

Forteza, Alvaro, e Guzmán Ourens. 2009. "How Much Do Latin American Pension Programs Promise to Pay Back?”. Social Protection Discussion Paper 0927. Washington, D.C. http://documents.worldbank.org/curated/ en/773451468047801758/How-much-do-Latin-American-pension-programs-promise-to-pay-back. 
Genser, Bernd, e Robert Holzmann. 2020. "Pensions in a Globalizing World: How Do (N)DC and (N)DB Schemes Fare and Compare on Portability and Taxation?" In Progress and Challenges of Nonfinancial Defined Contribution Pension Schemes, Volume 2: Addressing Gender, Administration and Communication, editado por Robert Holzmann, Edward Palmer, Robert Palacios, e Stefano Sacchi, 289-316. Washington, D.C.: The World Bank. https://openknowledge.worldbank.org/handle/10986/32439.

Godínez-Olivares, Humberto, María del Carmen Boado-Penas, e Steven Haberman. 2016. "Optimal Strategies for Pay-as-You-Go Pension Finance: A Sustainability Framework." Insurance: Mathematics and Economics 69 (July): 117-26. https://doi.org/10.1016/j.insmatheco.2016.05.001.

Greenwood, Michael J., e John M. McDowell. 2011. "USA Immigration Policy, Source-Country Social Programs, and the Skill Composition of Legal USA Immigration.” Journal of Population Economics 24, no.2: 521-39. https://doi.org/10.1007/s00148-009-0273-4.

Greenwood, Michael J., John M. McDowell, Donald M. Waldman, e Steven S. Zahniser. 1999. “The Influence of Social Programs in Source Countries on Various Classes of U.S. Immigration.” Journal of the American Statistical Association 94, no.445: 64-74. https://doi.org/10.1080/01621459.1999.10473819.

Gustman, Alan L., e Thomas L. Steinmeier. 2001. "How Effective Is Redistribution under the Social Security Benefit Formula?” Journal of Public Economics 82, no.1: 1-28. https://doi.org/10.1016/S0047-2727(00)00153-5.

Holzmann, Robert. 2016. "Bilateral Social Security Agreements and Pensions Portability: A Study of Four Migrant Corridors between EU and Non-EU Countries." International Social Security Review 69, no.3-4: 109-30. https://doi.org/10.1111/issr.12110.

Holzmann, Robert, e Jacques Wels. 2020. "The Cross-border Portability of Social Security Benefits: Status and Progress?” International Social Security Review 73, no.1: 65-97. https://doi.org/10.1111/issr.12228.

Holzmann, Robert, Jacques Wels, e Pamela Dale. 2016a. “Assessing Benefit Portability for International Migrant Workers: A Review of the Austria-Turkey Bilateral Social Security Agreement." Social Protection \& Labor Discussion Paper 1602. Washington, D.C. http://documents.worldbank.org/curated/en/2016/06/26436651/assessing-benefit-portability-international-migrant-workers-review-austria-turkey-bilateral-social-security-agreement.

Holzmann, Robert, Jacques Wels, e Pamela Dale. 2016b. “Assessing Benefit Portability for International Migrant Workers: A Review of the Belgium-Morocco Bilateral Social Security Agreement." Social Protection \& Labor Discussion Paper 1603. Washington, D.C. http://documents.worldbank.org/curated/en/2016/06/26436648/assessing-benefit-portability-international-migrant-workers-review-belgium-morocco-bilateral-social-security-agreement.

Holzmann, Robert, Jacques Wels, e Pamela Dale. 2016c. “Assessing Benefit Portability for International Migrant Workers: A Review of the France-Morocco Bilateral Social Security Agreement." 1604. Social Protection \& Labor Discussion Paper 1604. Washington, D.C. http://documents.worldbank.org/curated/en/313201484110324776/ Assessing-benefit-portability-for-international-migrant-workers-a-review-of-the-France-Morocco-bilateral-social-security-agreement.

Holzmann, Robert, Jacques Wels, e Pamela Dale. 2016d. “Assessing Benefit Portability for International Migrant Workers: A Review of the Germany-Turkey Bilateral Social Security Agreement." Social Protection \& Labor Discussion Paper 1606. Washington, D.C. http://documents.worldbank.org/curated/en/2016/06/26442094/assessing-benefit-portability-international-migrant-workers-review-germany-turkey-bilateral-social-security-agreement.

Holzmann, Robert, e Martin Werding. 2015. "Portability of Social Benefits: Research on a Critical Topic in Globalization.” CESifo Economic Studies 61, no.2: 335-45. https://doi.org/10.1093/cesifo/ifv009.

INSS. 2007. "Convenção Multilateral Ibero-Americana de Segurança Social.” Brasília: INSS. https://www.inss. gov.br/wp-content/uploads/2017/07/Convencao-Multilateral-Iberoamericana-Seguranca-Social.pdf.

INSS. 2019. “Agora é 86/96: Fórmula Para Cálculo Do Valor Da Aposentadoria Por Tempo de Contribuição é Atualizado.” INSS. 2019. https://www.inss.gov.br/agora-e-86-96-formula-para-calculo-do-valor-da-aposentadoria-por-tempo-de-contribuicao-e-atualizado/.

International Labour Organization (ILO). 2014. "Facts on Social Security." 2014. https://www.ilo.org/wcmsp5/ groups/public/---dgreports/---dcomm/documents/publication/wcms_067588.pdf.

Estud. Econ., São Paulo, vol.51 n.1, p.73-109, jan.-mar. 2021 
International Social Security Association (ISSA). 2010. "Demographic Changes and Social Security: Challenges and Opportunities." In World Social Security Forum. 30th ISSA General Assembly, 21. Cape Town: International Social Security Association.

ISSA. 2018. "10 Global Challenges for Social Security. Asia and Pacific." Geneva. https://www.issa.int/en/-/ 10-global-challenges-for-social-security-asia-pacific.

La Fuente, Angel De, e Rafael Domenéch. 2013. "The Financial Impact of Spanish Pension Reform: A Quick Estimate." Journal of Pension Economics and Finance 12, no.01: 111-37. https://doi.org/10.1017/ S1474747212000182.

Labouré, Marion. 2019. "Pensions: The Impact of Migrations and Cross-Border Workers in a Small Open Economy." Journal of Pension Economics and Finance 18, no.2: 247-70. https://doi.org/10.1017/S1474747217000464.

Lacomba, Juan A., e Francisco Lagos. 2010. "Immigration and Pension Benefits in the Host Country." Economica 77, no.306: 283-95. https://doi.org/10.1111/j.1468-0335.2008.00770.x.

Lee, Everett S. 1966. “A Theory of Migration.” Demography 3, no.1: 47. https://doi.org/10.2307/2060063.

Lewis, W. Arthur. 1954. "Economic Development with Unlimited Supplies of Labour." The Manchester School 22, no.2: 139-91. https://doi.org/10.1111/j.1467-9957.1954.tb00021.x.

Liddo, Giuseppe Di. 2018. "Immigration and PAYG Pension Systems in the Presence of Increasing Life Expectancy.” Economics Letters 162 (January): 56-61. https://doi.org/10.1016/j.econlet.2017.10.024.

Liebman, Jeffrey B. 2002. "Redistribution in the Current U.S. Social Security System." In The Distributional Aspects of Social Security and Social Security Reform, editado por Martin Feldstein e Jeffrey B. Liebman, I:11-48. Cambridge, MA.: University of Chicago Press. http://www.nber.org/chapters/c9747.pdf.

Lopez, Mary J., e Sita Slavov. 2019. “Do Immigrants Delay Retirement and Social Security Claiming?” NBER Working Paper Series 25518. Cambridge, MA. http://www.nber.org/papers/w25518.

Barbon, Júlia. 2017. "Lei de Migração: O Que Muda Nas Regras Para Estrangeiros No Brasil.” Folha de São Paulo, Maio 14, 2017. https://www1.folha.uol.com.br/cotidiano/2017/05/1883696-lei-de-migracao-o-que-muda-nas-regras-para-estrangeiros-no-brasil.shtml

Massey, Douglas S., Joaquin Arango, Graeme Hugo, Ali Kouaouci, Adela Pellegrino, e J. Edward Taylor. 1993. "Theories of International Migration: A Review and Appraisal." Population and Development Review 19, no.3: 431. https://doi.org/10.2307/2938462.

Massey, Douglas S., Joaquin Arango, Graeme Hugo, Ali Kouaouci, Adela Pellegrino, e J. Edward Taylor. 1998. Worlds in Motion: Understanding International Migration at the End of the Millenium. Oxford: Clarendon Press.

Ministerio de Empleo y Seguridad Social (MESS). 2019. “Bases y Tipos de Cotización 2016.” Madrid: Ministerio de Empleo y Seguridad Social. http://www.seg-social.es/wps/portal/wss/internet/Trabajadores/CotizacionRecaudacionTrabajadores $/ 36537$.

Modigliani, Franco, e Richard Brumberg. 1954. "Utility Analysis and The Consumption Function: An Interpretation of Cross-Section Data." In PostKeynesian Economics, editado por K. Kurihara, 388-436. New Brunswick: Rutgers University Press.

Neysmith, Sheila M., e Jane Aronson. 2012. "Global Aging and Comparative Research: Pushing Theoretical and Methodological Boundaries." Journal of Aging Studies 26, no.3: 227-31. https://doi.org/10.1016/j.jaging.2012.02.001.

Pallares-Miralles, Montserrat, Carolina Romero, e Edward Whitehouse. 2012. "International Patterns of Pension Provision II: A Worldwide Overview of Facts and Figures." Social Protection \& Labor Discussion Paper 1211. Washington, D.C. http://documents.worldbank.org/curated/en/143611468168560687/pdf/703190NWP0SPL000Box370035B00PUBLIC0.pdf.

Quinn, Joseph F. 1999. "Criteria for Evaluating Social Security Reform.” In Prospects for Social Security Reform, editado por Olivia S. Mitchell, Robert J. Myers, e Howard Young, 37-59. Philadelphia: University of Pennsylvania Press. https://pensionresearchcouncil.wharton.upenn.edu/publications/books/prospects-for-social-security-reform/. 
Ranis, Gustav, e John C. H. Fei. 1961. “A Theory of Economic Development.” The American Economic Review LI: 533-65. https://www.jstor.org/stable/1812785.

Ravenstein, Ernst Georg. 1889. “The Laws of Migration.” Journal of the Royal Statistical Society 52: 241-305.

Sabates-Wheeler, Rachel, e Johannes Koettl. 2010. "Social Protection for Migrants: The Challenges of Delivery in the Context of Changing Migration Flows." International Social Security Review 63, no.3-4: 115-44. https:// doi.org/10.1111/j.1468-246X.2010.01372.x.

Santos, Mauro Augusto dos, Alisson Flávio Barbieri, José Alberto Magno de Carvalho, e Carla Jorge Machado. 2010. "Migração: Uma Revisão Sobre Algumas Das Principais Teorias." Textos Para Discussão 398. Belo Horizonte. https://core.ac.uk/download/pdf/6314064.pdf.

Settergren, Ole, e Boguslaw D. Mikula. 2005. "The Rate of Return of Pay-as-You-Go Pension Systems: A More Exact Consumption-Loan Model of Interest." Journal of Pension Economics and Finance 4, no.2: 115-38. https:// doi.org/10.1017/S1474747205002064.

Sevak, Purvi, e Lucie Schmidt. 2014. "Immigrants and Retirement Resources.” Social Security Bulletin 74, no.1: 27-45. https://www.ssa.gov/policy/docs/ssb/v74n1/v74n1p27.html.

Sjaastad, Larry A. 1962. "The Costs and Returns of Human Migration.” Journal of Political Economy 70, no.5: 80-93. https://www.jstor.org/stable/1829105\%0A.

Skeldon, Ronald. 2012. "Migration Transitions Revisited: Their Continued Relevance for The Development of Migration Theory." Population, Space and Place 18, no.2: 154-66. https://doi.org/10.1002/psp.667.

Social Security Administration (SSA) e International Social Security Association (ISSA). 2016. "Social Security Programs Throughout the World: Europe, 2016.” Washington, D.C. http://www.ssa.gov/policy/docs/progdesc/ ssptw/2012-2013/asia/qatar.html.

Tamagno, Edward. 1994. "Coordination of Social Security Programmes of Developed and Developing Countries." International Social Security Review 47, no.1: 3-13. https://doi.org/10.1111/j.1468-246X.1994.tb01097.x.

Taylor, J. E. 1986. "Differential Migration,Networks, Information and Risks." In Research in Human Capital and Development, editado por Oded Stark, 147-71. Greenwich, CT.: JAI Press.

Todaro, Michael P. 1969. "A Model of Labor Migration and Urban Unemployment in Less Developed Countries." The American Economic Review 59, no.1: 138-49. https://www.jstor.org/stable/1811100.

United Nations. 2017. "The World Counted 258 Million International Migrants in 2017, Representing 3.4 per Cent of Global Population." Popfacts December, no. 5: 1-4. http://www.un.org/en/development/desa/population/ migration/publications/populationfacts/docs/MigrationPopFacts20175.pdf.

Whiteford, Peter. 1995. "The Use of Replacement Rates in International Comparisons of Benefit Systems." International Social Security Review 48, no.2: 3-30. https://doi.org/10.1111/j.1468-246X.1995.tb00427.x. 